\title{
Estrutura, composição florística e similaridade na Floresta Ombrófila Densa Atlântica, em áreas do Parque Estadual da Serra do Mar, Núcleo Caraguatatuba

\author{
Structure, floristic composition and similarity in the Atlantic Ombrophilous Dense Forest, \\ in areas of the Serra do Mar State Park, Caraguatatuba Center
}

\author{
Edson Junior Ferreira Stefani' (1) Jorge Yoshio Tamashiro' (1) | Carlos Alfredo Joly' (1) \\ Universidade Estadual de Campinas. Departamento de Biologia Vegetal. Campinas, São Paulo, Brasil
}

\begin{abstract}
Resumo: É necessário compreender a diversidade da Mata Atlântica para monitorar possíveis impactos das mudanças climáticas e mitigar o desaparecimento deste hotspot de biodiversidade. Apresentamos dados do Parque Estadual da Serra do Mar, Núcleo Caraguatatuba (NCR), com objetivo principal do conhecimento florístico, fitossociológico e similaridade das áreas florestais. Os dados foram coletados em parcelas permanentes de 1 ha, incluindo espécies com diâmetro $\geq 15 \mathrm{~cm}$ (PAP; 1,30 m de altura do solo), para conhecimento das áreas e para testes de similaridade entre as parcelas dos núcleos Picinguaba e Santa Virgínia, de mesma cota altitudinal. São apresentados tabelas florísticas das áreas, análise de UPGMA e teste de Mantel, para verificar o agrupamento das áreas. As famílias com maior índice de valor de importância foram Euphorbiaceae, Myrtaceae, Rubiaceae, Lauraceae, Arecaceae e Fabaceae, na parcela do NCR Submontana 1, e Myrtaceae, Sapotaceae, Monimiaceae, Nyctaginaceae, Lauraceae, Arecaceae e Rubiaceae, na parcela do NCR Montana 1. Através dos testes, foi possível verificar similaridades entre as áreas. Em alguns casos, ocorreu dissimilaridade, que estaria ligada a possíveis fatores ambientais e antrópicos, os quais não foram testados para afirmação, sugerindo estudos futuros a médio e longo prazo.
\end{abstract}

Palavras-chave: Diversidade arbórea. Mata Atlântica. Similaridade entre áreas.

\begin{abstract}
In order to monitor possible impacts of climate change and mitigate the disappearance of the Atlantic Forest biodiversity hotspot, it is necessary to understand its diversity. We present data from the Serra do Mar State Park (PESM), Caraguatatuba Center (NCR) with the main objective of floristic, phytosociological knowledge and similarity of forest areas. The data were collected in permanent plots of 1 ha, including species with a diameter $\geq 15 \mathrm{~cm}$ (PAP; $1.30 \mathrm{~m}$ above the ground) for knowledge of the areas and for similarity tests between the plots of the Picinguaba and Santa Virgínia Center, from the same altitudinal range. Floristic tables of the areas, UPGMA analysis and Mantel test are presented to verify the grouping of the areas. The families with the highest Importance Value Index were Euphorbiaceae, Myrtaceae, Rubiaceae, Lauraceae, Arecaceae and Fabaceae in the NCR Submontana 1 plot and Myrtaceae, Sapotaceae, Monimiaceae, Nyctaginaceae, Lauraceae, Arecaceae and Rubiaceae in the NCR Montana 1 plot. By carrying out tests it was possible to evaluate similarities between the areas. In some cases, there was dissimilarity, which could be linked to possible environmental factors and anthropic factors, but the confirmation of which was not tested, suggesting future studies in the medium and long term.
\end{abstract}

Keywords: Tree diversity. Atlantic Forest. Similarity of areas.

\footnotetext{
Stefani, E. J. F., Tamashiro, J. Y., \& Joly, C. A. (2021). Estrutura, composição florística e similaridade na Floresta Ombrófila Densa Atlântica, em áreas do Parque Estadual da Serra do Mar, Núcleo Caraguatatuba. Boletim do Museu Paraense Emílio Goeldi. Ciências Naturais, 16(2), 177-202. http://doi.org/10.46357/bcnaturais.v16i2.297.

Autor para correspondência: Edson Junior Ferreira Stefani. Rua Monteiro Lobato, 255. Campinas, SP, Brasil. CEP $13083-862$ (juniorferreirastefani@gmail.com).

Recebido em 26/03/2020

Aprovado em 12/04/2021

Responsabilidade editorial: Débora Rodrigues Souza-Campana
}
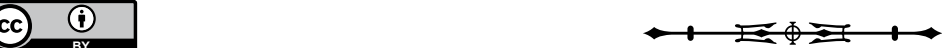


\section{INTRODUÇÃO}

AMata Atlântica é considerada um hotspot da biodiversidade brasileira (Myers, 2000) que abriga centenas de espécies animais, sendo estimadas cerca de 20 mil espécies vegetais (Brasil, 2020). Essas florestas são responsáveis pelos serviços ecossistêmicos das sociedades humanas, que podem ser gerados diretamente ou indiretamente e incluem a provisão do ciclo da água, da regulação dos gases e do clima, da ciclagem dos nutrientes e de diversos outros fatores que garantem o bem-estar do homem (Andrade \& Romeiro, 2009).

O homem modifica as paisagens florestais, causando grandes alterações, através do uso do solo, da degradação dos ambientes naturais, aumentando a poluição da atmosfera e usando de forma insustentável os serviços ecossistêmicos, disponibilizados por meio de processos naturais de preservação do meio ambiente (Joly et al., 2014). As florestas tropicais estão expostas em níveis crescentes de perturbações relacionadas às atividades antrópicas, que trazem consequências negativas ao próprio bem-estar humano (Wright, 2005; Krug, 2008; Joly et al., 2014; Alves \& Marinho, 2015), gerando problemas como a crise hídrica, o uso de diversos agrotóxicos nos alimentos, que também poluem o meio ambiente, além da influência na saúde do homem, da falta de saneamento básico e de outros fatores (Soares et al., 2002).

Essas alterações, combinadas com ameaças emergentes da mudança climática global como resultado das emissões dos gases do efeito estufa (GEE) (Uhlig et al., 2008), têm sido determinantes para o desequilíbrio do balanço de energia do sistema terra-atmosfera (Andrade \& Romeiro, 2011). Tais alterações ambientais estão causando perda alarmante de biodiversidade e colapso dos principais serviços ecossistêmicos (Siche et al., 2007; Butchart et al., 2010; Pinheiro \& Durigan, 2012). Poluentes provenientes de grandes empreendimentos, como polos petroquímicos, podem provocar grandes distúrbios na composição, estrutura e funcionamento das áreas naturais que estão sob sua influência direta ou até mesmo indireta
(Abbas et al., 1993; Leitão Filho et al., 1993; Klumpp et al., 1994, 1996, 1998; Domingos et al., 2000; Stewart et al., 2002).

No trabalho realizado em Cubatão, no estado de São Paulo, por Klumpp et al. (1996), foi considerado que os fluoretos gasosos emitidos naquela área promoveram o declínio da floresta. Já Freitas et al. (2005) constataram que as emissões de queimadas em ecossistemas na América do Sul são fontes de poluentes para os países desta região, tornando mais grave a situação de impacto nas florestas, transformando o impacto local em continental.

A Floresta Atlântica sofre bastante com a influência antrópica, principalmente com desmatamento, desenvolvimento industrial e expansão urbana, que trazem como consequências diversos distúrbios ambientais relacionados à perda da biodiversidade. Todos esses fatores podem, ainda, causar a diminuição da frequência de diversas espécies da Mata Atlântica, inclusive alterações climáticas, provocando mudança na temperatura do planeta em nível global e até mesmo da Serra do mar em nível local, ocasionando processos de migração das espécies para outras áreas (Joly et al., 2014).

A Mata Atlântica sensu lato (MA) (Fundação S.O.S. Mata Atlântica, 1992) sofreu e continua sofrendo com os impactos ambientais de todos os ciclos econômicos do país, da extração do 'pau-brasil' (Paubrasilia echinata (Lam.) Gagnon, H.C.Lima \& G.P.Lewis) no século XVI à substituiç̧ão por Eucalyptus spp., resultante da expansão da indústria de papel e celulose no século XXI (Joly et al., 2014). Além disso, existem diversos outros fatores de insustentabilidade e de alterações que estão conectados à perda da manutenção dos serviços ecossistêmicos.

Em consequência desse longo período de perturbações, e considerando as áreas de floresta secundária e fragmentos com menos que 100 ha, restam, hoje, cerca de 12,4\% da cobertura original da MA (Junior et al., 2019). Grande parte desses remanescentes está imersa em uma matriz altamente antropizada (Tabarelli et al., 2010), sob forte ameaça de expansão urbana, infraestrutura viária 
e instalação de novos empreendimentos ligados à indústria de gás e petróleo (Salati et al., 2006; Ribeiro \& Freitas, 2010).

O Núcleo Caraguatatuba do Parque Estadual da Serra do Mar (PESM), local do presente estudo, está sujeito a futuros impactos diretos, com a duplicação da rodovia dos Tamoios e a construção do anel viário de Caraguatatuba, e indiretos, com a emissão de poluentes, especialmente óxidos de nitrogênio ( $N O x$ ), o funcionamento da Unidade de Tratamento de Gás de Caraguatatuba (UTGCA), cujo início foi no ano de 2012, alguns meses após as coletas dos dados deste trabalho. funcionamento da UTGCA promove deposição dos poluentes liberados na atmosfera. Dessa forma, o acompanhamento, a curto, médio e longo prazo, é necessário e continua sendo realizado nesta área amostral.

Alterações ambientais como essas podem ser comparadas ao histórico de influências sofrido pelas florestas em Cubatão, no litoral paulista (Moraes et al., 2000). A influência antrópica em Cubatão pode ser usada como exemplo para possíveis danos ao funcionamento florestal das áreas do PESM no Núcleo Caraguatatuba. Moraes et al. (2000) descrevem a ocorrência da alteração no processo de fotossíntese líquida, no crescimento e na química foliar de espécies da floresta atlântica no entorno de Cubatão.

A deposição de compostos de $\mathrm{NOx}$ e $\mathrm{CO}_{2}$ derivados das emissões gasosas, com múltiplos impactos sobre a vegetação da região, também é observada em estudos na região de Cubatão, São Paulo, em áreas próximas ao polo petroquímico (Klumpp et al., 1998). Estes pontos destacam que a grande poluição atmosférica da região altera principalmente a composição vegetal da floresta daquelas áreas. Além da composição atmosférica da área atingida, pode, consequentemente, alterar as taxas de deposição seca na superfície das folhas e do solo (Stewart et al., 2002). Sobretudo, pode também alterar a fisiologia das plantas, uma vez que a poluição se torna disponível para a absorção da planta e para infiltração no solo, podendo ser, inclusive, fitotóxica para a superfície foliar. Além disso, a emissão desses gases pode contribuir, a longo prazo, para o aumento dos gases do efeito estufa e, consequentemente, para a ocorrência de alteração na composição florística e fitossociológica (Bueno et al., 2017).

Essas alterações podem ser, inclusive, ocasionadas pelas mudanças de temperatura segundo os modelos climáticos computacionais, que estimam aquecimento em partes do país ao final do século XXI (Pachauri \& Meyer, 2014). Outros fatores estão ligados a curto prazo com reações químicas nas camadas superficiais do solo (Mayer et al., 2000) e com a poluição da atmosfera, que interage com o ar, trazendo danos à saúde da população, como já foi relatado em trabalhos realizados na floresta amazônica (Artaxo et al., 2006).

A localização da UTGCA e as peculiaridades climáticas da região do presente estudo podem favorecer a contaminação da água da chuva (Högberg, 2007), alterando o balanço de nutrientes e mudando a relação de competição entre espécies, causando queda e alteração na diversidade florística em longo prazo (Bueno et al., 2017). Assim, torna-se imprescindível que façamos o diagnóstico destas áreas do NCR que estão na vertente direcional à UTGCA e que poderão receber a pluma de poluição da usina. Com isso, poderemos monitorar a posteriori o funcionamento da floresta através dos possíveis impactos deste empreendimento, utilizando a determinação da estrutura e da composição florística da floresta estudada neste trabalho.

Dessa forma, os objetivos deste trabalho são contribuir para o conhecimento da florística e da fitossociologia da Floresta Ombrófila Densa Atlântica no NCR do PESM, para que possamos conhecer os aspectos estruturais e as espécies que ocorrem nesta área, estabelecendo uma linha de base sobre estes componentes antes do início do funcionamento da UTGCA; verificar a similaridade desta área com áreas sem influência da UTGCA, no Núcleo Santa Virgínia (NSV) e no Núcleo Picinguaba (NPC), que também são áreas do PESM, para verificarmos possíveis influências antrópicas no NCR; por fim, monitorar as possíveis mudanças que ocorrem no tempo, consequências provenientes do aquecimento global 
e das prováveis poluições atmosféricas nestas áreas florestais (Malhi et al., 2002; Lewis et al., 2004; Eisenlohr \& Oliveira Filho, 2015; J. Pereira et al., 2015).

\section{MATERIAL E MÉTODOS}

\section{ÁREA DE ESTUDO}

O estudo e a coleta de dados deste trabalho foram realizados no Parque Estadual da Serra do Mar (PESM). Este parque ocupa uma área de 332 mil hectares, que percorrem uma extensão que vai desde a divisa do estado de São Paulo com o Rio de Janeiro até o litoral sul de São Paulo, compreendendo 25 municípios. A área de estudo (Figura 1) está inserida no Núcleo Caraguatatuba (NCR), município de Caraguatatuba (litoral norte do estado de São Paulo). Estas áreas, de acordo com Veloso et al. (1991), são classificadas como Floresta Ombrófila Densa (FOD) Submontana - 50 a 500 m de altitude - e FOD Montana - 500 a 1.500 m. As parcelas do NCR estão instaladas na vertente da Serra do Mar e foram selecionadas considerando-se as áreas de influência das emissões gasosas da Unidade de Tratamento de Gás de Caraguatatuba (UTGCA) (Figura 1).

A UTGCA é o polo de gás e petróleo que conta com um gasoduto submarino de $172 \mathrm{~km}$ de extensão, responsável por transportar o gás até a costa na UTGCA. Com a duplicação do porto de São Sebastião, a construção do anel viário de Caraguatatuba e a duplicação da rodovia dos Tamoios, esta região passou a contar com outros dois gasodutos, um que transporta os componentes nobres do gás de Mexilhão para o porto de São Sebastião e outro que transporta os demais componentes serra acima, conectado à rede de gasodutos que corta o vale do Paraíba.

Contudo, o polo de gás e petróleo instalado nos municípios de Caraguatatuba e São Sebastião para exploração dos campos de Mexilhão, Tupi e do Pré-Sal teve seu funcionamento iniciado a partir de abril de 2012, pouco tempo após a coleta dos dados deste trabalho, que ocorreu em 2010, na FOD Submontana, e em 2011, na FOD Montana, ambas no NCR.

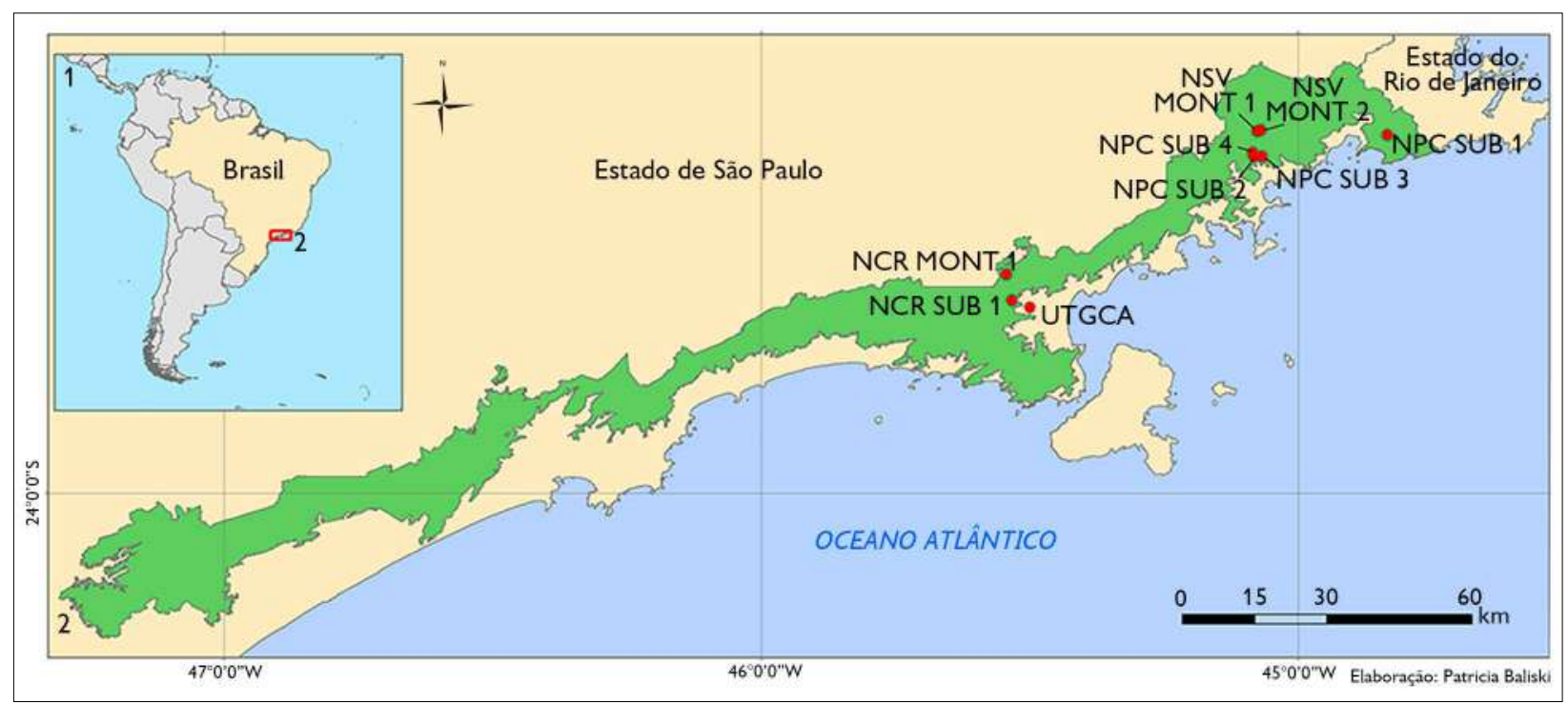

Figura 1. Áreas amostradas no Parque Estadual da Serra do Mar, Floresta Ombrófila Densa Submontana, Núcleo Caraguatatuba (NCR) Submontana NCR SUB 1 (107-140 m), Caraguatatuba, São Paulo; Núcleo Picinguaba (NPC) Submontana NPC SUB 1 (64-89 m), NPC SUB 2 (176-198 m), NPC SUB 3 (200-216 m) e NPC SUB 4 (325-374 m), Ubatuba, São Paulo; áreas de Montana NCR MONT 1 (790-812 m), Caraguatatuba, São Paulo; Núcleo Santa Virgínia (NSV) Montana NSV MONT 1 (1040-1100 m) e Montana NSV MONT 2 (1010-1093 m), em São Luís do Paraitinga, São Paulo; e Unidade de Tratamento de Gás de Caraguatatuba (UTGCA). Mapa: Patricia Baliski (2020).

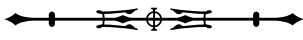


Além da coleta de dados no NCR Submontana 1 e Montana 1 para o acompanhamento e conhecimento da florística e fitossociologia das áreas, foram feitas comparações amostrais com as parcelas que pertencem ao PESM do Núcleo Picinguaba (NPC) e Núcleo Santa Virgínia (NSV) e apresentam altitude semelhante à das parcelas do NCR, para devida comparação.

Para a comparação, foram incluídas as parcelas NPC Submontana 1, Submontana 2, Submontana 3, Submontana 4 e NSV Montana 1 e Montana 2, a fim de se verificar a similaridade entre as áreas que estão sob influência da UTGCA no NCR. Sendo assim, as parcelas pertencentes ao NCR instaladas próximo à UTGCA foram comparadas com as parcelas fora desta vertente, no NPC e NSV que não recebem emissões da usina.

Nas parcelas de estudo, ocorrem dois compartimentos geomorfológicos básicos: um formado por escarpas e rampas de aplainamento, com vários níveis altimétricos, e um composto por morros e colinas de baixa amplitude altitudinal, situados no planalto, entre 50 a 1.300 m (S. Martins, 2010). O solo é classificado como Cambissolo háplico distrófico típico, argiloso, ácido ( $\mathrm{pH}$ 3,3 a 3,9), com alta diluição de nutrientes e alta saturação de alumínio (S. Martins, 2010). Na floresta Submontana, a textura encontrada foi argilo-arenosa e na Montana, franco argiloarenosa. Em ambas, ocorrem áreas muito pedregosas e afloramentos rochosos de granito/gnaisse formados durante a era pré-cambriana. $\bigcirc$ solo possui ainda quartzo, gibsita e ilita, denotando um alto grau de intemperismo, com ocorrência de quartzo de textura mais arenosa e natureza quartzosa (S. Martins, 2010).

\section{DESCRIÇÃO DAS PARCELAS AMOSTRAIS}

Na coleta de dados deste trabalho, foram instaladas parcelas de 1 ha amostrais nas áreas da Floresta Ombrófila Densa (FOD) Submontana, localizadas no Núcleo Caraguatatuba (NCR) (2338' 26" Se 4531' 57" W), que foi denominada como NCR Submontana 1, com altitude variando entre 107 a 140 m (Figura 1). $\bigcirc$ clima é definido como subtropical úmido (Cfa), seguindo o sistema de classificação de Köeppen (1948), sendo que a temperatura média anual é de $25^{\circ} \mathrm{C}$, sem estação seca definida. As precipitações médias anuais variam entre 1.200 e 2.500 mm/ano (Stefani, 2013).

Para comparação entre áreas da FOD Submontana, foram usadas as áreas do Núcleo Picinguaba, denominadas

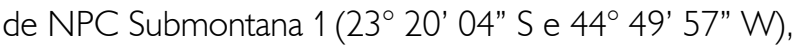

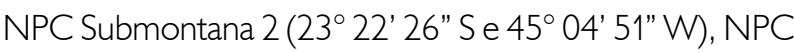
Submontana 3 ( $23^{\circ} 22^{\prime} 01^{\prime \prime} \mathrm{S}$ e $45^{\circ} 05^{\prime}$ '01" W) e NPC Submontana 4 (2322' 01" S e $45^{\circ} 05^{\prime} 01^{\prime \prime}$ W) (Figura 1). As parcelas estão localizadas no município de Ubatuba, São Paulo, com clima regional Af, na classificação de Köeppen (1948), com temperatura média anual de $22^{\circ} \mathrm{C}$ e pluviosidade média anual de $2.600 \mathrm{~mm} / \mathrm{ano}$ (Campos et al., 2011; Gomes et al., 2011; Ramos et al., 2011).

Também foram coletados dados neste trabalho para a FOD Montana no NCR (233' 37" S e 45 32' 32" W) (Figura 1). A parcela instalada nesta área foi denominada de NCR Montana 1. A altitude dessa parcela varia entre 790 a 812 m acima do nível do mar. O clima é definido como subtropical úmido (Cfa, de Köeppen), sendo que a temperatura média anual é de $20,4^{\circ} \mathrm{C}$, sem estação seca definida. As precipitações médias anuais situam-se em torno de 1.600 mm/ano (Veneziani et al., 2009).

Os dados utilizados para comparação com o NCR foram também das áreas do PESM do Núcleo Santa Virgínia (NSV), denominadas NSV Montana 1 (23 19' 36" S e $45^{\circ}$

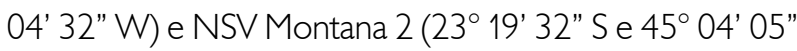
W) (Figura 1). Estas parcelas estão localizadas no município de São Luís do Paraitinga, São Paulo, com clima regional do tipo Cwa, na classificação de Köeppen (1948), com temperatura média anual de $21^{\circ} \mathrm{C}$ e pluviosidade média anual de $2.500 \mathrm{~mm}$ (Padgurschi et al., 2011).

\section{COLETA DE DADOS E DEMARCAÇÃO DOS INDIVÍDUOS PARA FLORÍSTICA E FITOSSOCIOLOGIA}

Para que os indivíduos fossem coletados e demarcados dentro das parcelas amostrais nas áreas do Parque Estadual 
da Serra do Mar, no município de Caraguatatuba, São Paulo, foram estabelecidas duas parcelas permanentes, de um hectare cada, no Núcleo Caraguatatuba (NCR). Cada uma foi subdividida em 100 subparcelas de $10 \times 10 \mathrm{~m}$.

Para as parcelas do NPC e NSV, na comparação das áreas, foram utilizados os bancos de dados para parcelas permanentes implantadas em Ubatuba e São Luís do Paraitinga, São Paulo, que são padrões seguidos para coletas de florística e fitossociologia. Os detalhes do método de implantação e da coleta destas informações podem ser conferidos em Joly \& Martinelli (2008).

Para a coleta das parcelas do NCR, todos os indivíduos arbóreos vivos, incluindo palmeiras e pteridófitas (fetos arborescentes), e todos os mortos em pé e/ou ligeiramente tombados $\left(<30^{\circ}\right)$ com perímetro à altura do peito (PAP; $1,30 \mathrm{~m}$ de altura do solo) $\geq 15 \mathrm{~cm}$, foram plaqueados.

Os indivíduos que apresentaram bifurcações ou rebrotas ('perfilhos') abaixo de 1,30 m tiveram plaqueados apenas os caules dentro do perímetro de inclusão com PAP $\geq 15 \mathrm{~cm}$. Neste caso, o caule principal (com maior PAP) recebeu a placa de metal e os demais, uma placa de plástico branca.

Os indivíduos mortos foram apenas considerados na contagem de indivíduos na parcela e na área basal. Cada um foi plaqueado com uma placa de alumínio. Foi feito o mapeamento de todos os indivíduos plaqueados, medindo-se a distância deles em relação aos eixos $X$ e $Y$ da subparcela, facilitando a localização dentro da mesma. A altura total foi estimada visualmente.

\section{LEVANTAMENTO FLORÍSTICO E FITOSSOCIOLÓGICO}

A coleta de material botânico dos indivíduos arbóreos seguiu as orientações descritas por Fidalgo \& Bononi (1984). As identificações foram feitas com auxílio de literatura especializada, de consultas a especialistas e por comparações com as coleções do Herbário da Universidade Estadual de Campinas (UEC). O material botânico coletado foi tombado neste herbário. As espécies estão classificadas nas famílias cuja circunscrição segue o sistema de classificação do Angiosperm Phylogeny Group (APG, 2016).

\section{ANÁLISE DE DADOS DA FITOSSOCIOLOGIA E COMPARAÇÕES ENTRE PARCELAS}

Para avaliar e comparar a estrutura e a composição florística e fitossociológica das parcelas NCR Submontana 1 e NCR Montana 1, neste trabalho, foram utilizados parâmetros fitossociológicos como densidade (D), densidade média (DM), frequência (Fr), dominância absoluta (AbsDo), densidades relativas (RelDe), área basal total (AbsT), altura média (AltM), índice de valor de importância (IVI) e família (Mueller-Dombois \& Ellenberg, 1974), descritos detalhadamente em F. Martins (1991). Foram calculados também altura média, diâmetro médio, índice de diversidade de Shannon ( $\mathrm{H}^{\prime}$ ) e equabilidade de Pielou (J') (Brower \& Zar, 1984). O programa utilizado para os cálculos foi o FITOPAC 2.1 (Shepherd, 2010).

Para avaliar a distância florística entre as parcelas do NCR, NPC e NSV, foi calculado o coeficiente de Bray-Curtis. Para a matriz de abundância, foram usados o método Unweighted Pair Group Method with Arithmetic Mean (UPGMA), a fim de gerar o dendrograma de similaridade, que calcula a média aritmética da similaridade (ou distância) da área amostral NCR com as áreas amostrais de comparações NPC e NSV. Neste cálculo, o índice de Jaccard, com a matriz que varia entre 0 (similaridade total) e 1 (dissimilaridade total), não considera as duplas-ausências e é influenciado pelas espécies dominantes (Valentin, 2000). O programa usado foi o Ambiente R (Development Core Team, 2010). Para verificar a dissimilaridade entre todas as áreas neste trabalho, foi feito um correlograma de teste de Mantel, utilizando-se três índices de dissimilaridade diferentes (Bray-Curtis, Jaccard e Morisita) entre as relações de similaridade composicional no que concerne às amostras, por meio do pacote Vegan do Ambiente R (Development Core Team, 2010). 


\section{RESULTADOS}

Na Floresta Ombrófila Densa NCR Submontana 1, foram plaqueados 2.269 indivíduos. Desse total, 87 estavam mortos, equivalendo a $3,8 \%$ do total; os demais somam 1.992 árvores (87,8\%), entre as quais 174 são 'palmeiras' $(7,7 \%)$ e 16 são 'samambaias' (0,7\%). Foram identificadas 186 espécies e morfotipos pertencentes a 49 famílias botânicas, sendo que $0,5 \%$ foram identificados somente até o nível de família e 0,4\% até o de gênero (Apêndice 1).

As famílias com maior índice de valor de importância (IVI) foram Euphorbiaceae $(49,9)$, Myrtaceae $(29,3)$, Rubiaceae $(29,3)$, Lauraceae $(18,5)$, Arecaceae $(17,9)$ e Fabaceae $(15,9)$, as quais, juntas, representam $45,5 \%$ do IVI total. Euphorbiaceae, a mais abundante, apresentou 459 indivíduos, sendo a espécie Mabea piriri Aubl. a mais numerosa (220 árvores), com IVI de 25,1, seguida por Rubiaceae - Bathysa mendoncaei K. Schum. (11,1) -, Malvaceae - Eriotheca pentaphylla (Vell. \& K.Schum.) A. Robyns (10,5)-, Euphorbiaceae - Actinostemon verticillatus (Klotzsch) Baill. $(9,72)$-, Sapotaceae - Chrysophyllum viride Mart. \& Eichler $(7,52)$-, Arecaceae - Astrocaryum aculeatissimum (Schott) Burret $(7,33)$ e Euterpe edulis Mart. $(7,11)$ - e Myrtaceae - Eugenia batingabranca Sobral $(6,46)$ (Apêndice 1).

Arecaceae está entre as famílias mais abundantes, observada em 71 subparcelas amostradas, e contribuiu com 174 indivíduos (7,6\% do total amostrado). Esta família foi representada por três espécies no Núcleo Caraguatatuba (NCR) Submontana 1: Astrocaryum aculeatissimum (Schott) Burret (82 indivíduos), Euterpe edulis Mart. (73) e Syagrus pseudococos (Raddi) Glassman (19 indivíduos).

A área basal total foi de $48,4 \mathrm{~m}^{2}$ ha-1. O diâmetro máximo obtido foi de $119,95 \mathrm{~cm}$ e o médio foi de $13,1 \mathrm{~cm}$ $( \pm 11,4)$. Entre as quatro classes de diâmetro estabelecidas $(\geq 15 \mathrm{~cm}, 15-30 \mathrm{~cm}, 30-50 \mathrm{~cm}$ e $>50 \mathrm{~cm}$ ), mais da metade dos indivíduos $(54,2 \%)$ pertenceu à menor classe $(>10 \mathrm{~cm})$. A altura foi distribuída em seis classes ( $>5 \mathrm{~m}$, 5,1-10 m, 10,1-15 m, 15,1-20 m, 20,1-25 m e > 25,1), onde a altura média foi de 9,9 m ( \pm 4,7) e a altura máxima obtida foi de 58 m para um indivíduo de Cariniana legalis (Mart.) Kuntze (Lecythidaceae). O índice de diversidade de Shannon foi de H' $=4,46$ nats/indivíduos e a equabilidade de Pielou foi de J' = 0,977 (Tabela 1).

Na Floresta Ombrófila Densa NCR Montana 1, foram plaqueados 1.909 indivíduos, entre os quais 1.673 eram árvores (87,7\%), 203 'palmeiras' (10,6\%) e 33 'samambaias' (1,7\%). Foram identificadas 150 espécies e morfotipos pertencentes a 40 famílias botânicas. Vinte indivíduos foram identificados somente até o nível de família; 38 indivíduos (2\%) foram identificados até o nível de gênero (Apêndice 2).

As familias com maiores índices de valor de importância (IVI) foram Myrtaceae (44), Sapotaceae (35,5), Monimiaceae $(24,2)$, Nyctaginaceae $(21,8)$, Lauraceae $(20,5)$, Arecaceae $(20,64)$ e Rubiaceae $(17,4)$, as quais representam $50 \%$ do IVI total. Sapotaceae inclui a espécie com maior IVI da área - Chrysophyllum viride Mart. \& Eichler $(24,6)$-, seguida de Arecaceae - Euterpe edulis (16,5) -, Nyctaginaceae Guapira cf. venosa (Choisy) Lundell $(7,5)$ e G. opposita (Vell.) Reitz $(7,09)$-, Molinimiaceae - Mollinedia pachysandra Perkins (7,03) -, Malvaceae - Eriotheca pentaphylla (Vell. \& K.Schum.) A. Robyns (6,86) -, Nyctaginaceae Guapira hirsuta (Choisy) Lundell $(6,85)$ - e Euphorbiaceae - Alchornea glandulosa Poepp. $(6,80)$ (Apêndice 2). Arecaceae também aparece entre as famílias de maior IVI, sendo representada com 204 indivíduos, pertencentes a três espécies: Astrocaryum aculeatissimum (Schott) Burret (1 indivíduo), Syagrus pseudococos (Raddi) Glassman (17) e Euterpe edulis Mart. (186).

A área basal total foi de $46,7 \mathrm{~m}^{2}$ ha-1. $\bigcirc$ diâmetro máximo obtido foi de $118 \mathrm{~cm}$ e o médio, de 13,1 cm ( $\pm 11,8)$. Mais da metade dos indivíduos (58,8\%) pertence à menor classe de diâmetro $(<10 \mathrm{~cm})$. A altura média obtida foi de $9,7 \mathrm{~m}( \pm 4,6)$ e a altura máxima foi de 29 m, onde 49,7\% dos indivíduos pertencem à segunda classe (5,1-10 m). 0 índice de diversidade de Shannon-Weiner foi de $\mathrm{H}^{\prime}=$ 4,30 nats/indivíduos e equabilidade de Pielou J' $=0,974$ (Tabela 1). De acordo com os resultados obtidos através 
Tabela 1. Levantamentos fitossociológicos em áreas de floresta Submontana e Montana. Legendas: Parcelas/altitude = parcelas amostrais e suas respectivas altitudes (NCR Submontana 1; NPC Submontana 1, 2, 3 e 4 e NCR Montana 1; NSV Montana 1 e 2); Ind./parc. = total de indivíduos coletados por parcela; n.sp. = número de espécie; Família= quantidade de famílias identificadas em cada área; H'= índice de diversidade de Shannon-Wienner (nats.indivíduo-1); J' = equabilidade de Pielou; ABsT = área basal total; AltM= altura média; DM = diâmetro médio; * = este trabalho.

\begin{tabular}{|c|c|c|c|c|c|c|c|c|c|}
\hline Parcelas/altitude & Referência & Ind./parc. & n.sp. & Família & $\mathrm{H}^{\prime}$ & J' & $\mathrm{ABsT}$ & AltM & DM \\
\hline $\begin{array}{c}\text { NCR } \\
\text { Submontana } 1 \\
(107-140 \mathrm{~m})\end{array}$ & Stefani (2013)* & 2.182 & 186 & 49 & 4,46 & 0,97 & 48,40 & 9,90 & 13,10 \\
\hline $\begin{array}{c}\text { NPC } \\
\text { Submontana } 1 \\
(64-89 \mathrm{~m})\end{array}$ & Campos (2011) & 1.274 & 142 & 41 & 4,06 & 0,82 & 32,14 & 8,20 & 13,94 \\
\hline $\begin{array}{c}\text { NPC } \\
\text { Submontana } 2 \\
(176-198 \mathrm{~m})\end{array}$ & $\begin{array}{l}\text { Gomes et al. } \\
\text { (2011) }\end{array}$ & 1.496 & 152 & 41 & 3,96 & 0,78 & 39,40 & 7,72 & 13,63 \\
\hline $\begin{array}{c}\text { NPC } \\
\text { Submontana } 3 \\
(200-216 \mathrm{~m}) \\
\end{array}$ & $\begin{array}{l}\text { Ramos et al. } \\
\text { (2011) }\end{array}$ & 1.528 & 152 & 44 & 4,05 & 0,80 & 37,78 & 6,95 & 14,01 \\
\hline $\begin{array}{c}\text { NPC } \\
\text { Submontana } 4 \\
(325-374 \text { m) }\end{array}$ & $\begin{array}{l}\text { Gomes et al. } \\
\text { (2011) }\end{array}$ & 1.993 & 203 & 50 & 4,33 & 0,94 & 57,30 & 9,25 & 13,55 \\
\hline $\begin{array}{c}\text { NCR Montana } 1 \\
(790-812 \mathrm{~m})\end{array}$ & Stefani (2013)* & 1.909 & 150 & 40 & 4,30 & 0,97 & 46,69 & 9,78 & 13,10 \\
\hline $\begin{array}{l}\text { NSV Montana } 1 \\
(1.040-1.100 \mathrm{~m})\end{array}$ & $\begin{array}{l}\text { Padgurschi } \\
\text { et al. (2011) }\end{array}$ & 1.851 & 189 & 43 & 3,72 & 0,70 & 40,20 & 9,10 & 12,74 \\
\hline $\begin{array}{l}\text { NSV Montana } 2 \\
(1.010-1.093 \mathrm{~m})\end{array}$ & $\begin{array}{l}\text { Padgurschi } \\
\text { et al. (2011) }\end{array}$ & 1.436 & 149 & 40 & 4,06 & 0,80 & 37,47 & 11,70 & 14,29 \\
\hline
\end{tabular}

do índice de Shannon para as parcelas amostrais, tanto do NCR quanto do NPC e do NSV, foram observados valores altos quando comparados com outras áreas e trabalhos semelhantes para a maioria das parcelas, resultando em grande diversidade florística, como pode ser acompanhado nos resultados (Tabela 1).

Em relação à similaridade das parcelas amostrais, quando comparados os dados estruturais das parcelas do NCR Submontana 1 com NCR Montana 1, verifica-se que a parcela Submontana 1 abriga maior quantidade de espécies do que a Montana 1. Uma outra informação com destaque é a existência de um grau de similaridade correspondente entre essas parcelas do NCR, quando comparadas com parcelas das outras áreas amostrais, mas ambas não formam um grupo propriamente dito. Ao ser analisado o dendrograma de similaridade (Figura 2), foi verificada a existência de dois blocos distintos, um formado por NPC Submontana 1, 2, 3 e 4 e outro formado por NCR Submontana 1 e NCR Montana 1, sendo que as áreas NSV Montana 1 e 2 não se agruparam com nenhuma outra área e, portanto, são as mais distintas floristicamente.

O NPC Submontana 2 e 3 é composto pelas duas áreas mais similares (com aproximadamente $70 \%$ de similaridade), onde as duas áreas juntas formaram um bloco com menor similaridade com as áreas NPC Submontana 1 e 4, que apresentam aproximadamente $45 \%$ de similaridade com o NPC Submontana 1 e 55\% com o NPC Submontana 4. Apesar de a parcela Submontana 4 do NPC ter se agrupado com NPC Submontana 2, 3 e 1, apresenta menos de $50 \%$ de semelhança com elas; o NCR Submontana 1 e o NCR Montana 1 são similares entre si, mas têm 30\% de similaridade apenas com o bloco formado 


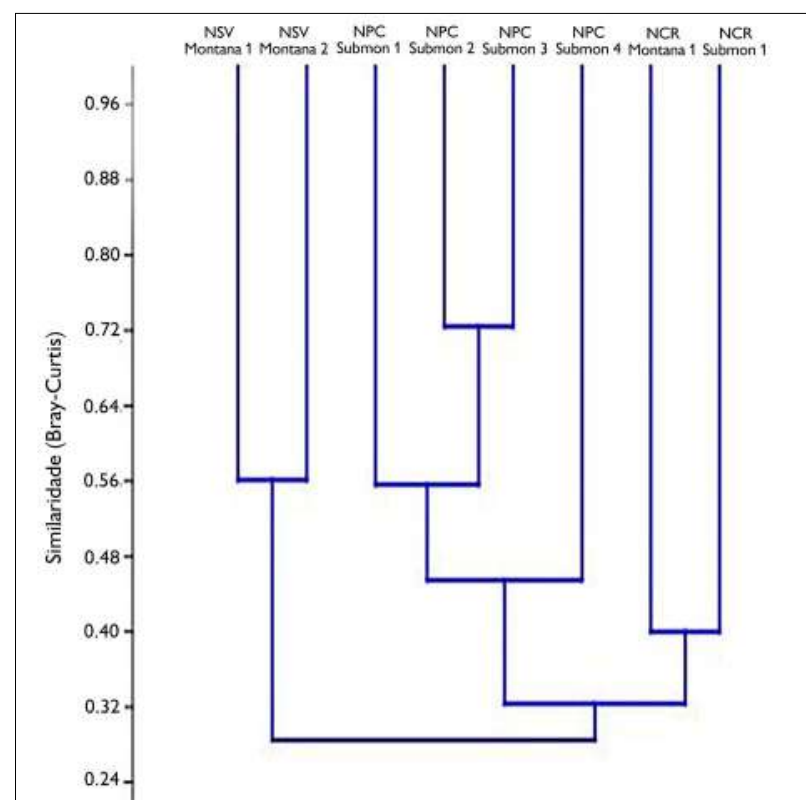

Figura 2. Dendrograma de similaridade (média de grupo UPGMA) em áreas de Floresta Ombrófila Densa NCR Submontana 1 (107-140 m), Caraguatatuba, São Paulo; NPC Submontana 1 (64-89 m), NPC Submontana 2 (176-198 m), NPC Submontana 3 (200-216 m) e NPC Submontana 4 (325-374 m), Ubatuba, São Paulo; e NCR Montana 1 (790-812 m), Caraguatatuba, São Paulo; NSV Montana 1 (1.040-1.100 m) e Montana 2 (1.010-1.093 m), São Luís do Paraitinga, São Paulo.

por NPC Submontana 1, 2, 3 e 4. Os resultados podem ser acompanhados na Figura 2. Contudo, através do teste de Mantel, com o índice de dissimilaridade, observa-se que não há efeito da distância geográfica na estruturação das comunidades, como pode ser visto na Figura 3.

\section{DISCUSSÃO}

No levantamento florístico da área amostral Núcleo Caraguatatuba (NCR), foram identificadas algumas espécies que são comuns a trabalhos realizados em áreas de mesma altitude, no Parque Estadual da Serra do Mar (PESM), as quais também são encontradas em áreas de regeneração natural (Garcia et al., 2011; Kunz \& Martins, 2013; Santos et al., 2018). Esses fatores sugerem que o PESM tem regiões que sofreram com os distúrbios ligados à influência antrópica (Abbas et al., 1993; Leitão Filho et al., 1993; Klumpp et al., 1994, 1996, 1998; Domingos et al., 2000; Stewart et al., 2002).
Tais influências podem ser responsáveis por uma maior susceptibilidade da floresta em receber outras espécies que não são comuns destas áreas, as quais acabam migrando para estas regiões por consequências tanto bióticas quanto abióticas de distúrbio, ou em razão do aumento de indivíduos de uma determinada espécie, que pode ser tanto endêmica quanto de ocorrência natural na floresta.

Mabea piriri Aubl. é uma espécie que pode ser encontrada em Guiana Francesa, Suriname, Guyana, Venezuela, Colômbia e, inclusive, no Brasil, nas regiões Norte, Nordeste, Centro-Oeste e Sudeste do país (Trindade, 2008; Hiura, 2011). A grande diversidade de locais onde esta espécie é encontrada mostra que há uma expressiva plasticidade quanto aos diferentes biomas. Foi relatado por Pscheidt \& Cordeiro (2012) que a espécie pode ser encontrada em Floresta Ombrófila, em altitudes de até $570 \mathrm{~m}$. Os autores destacam, ainda, que ela foi coletada em diversas áreas do litoral de São Paulo, inclusive em encosta da Serra do Mar, como ocorre também no presente trabalho.

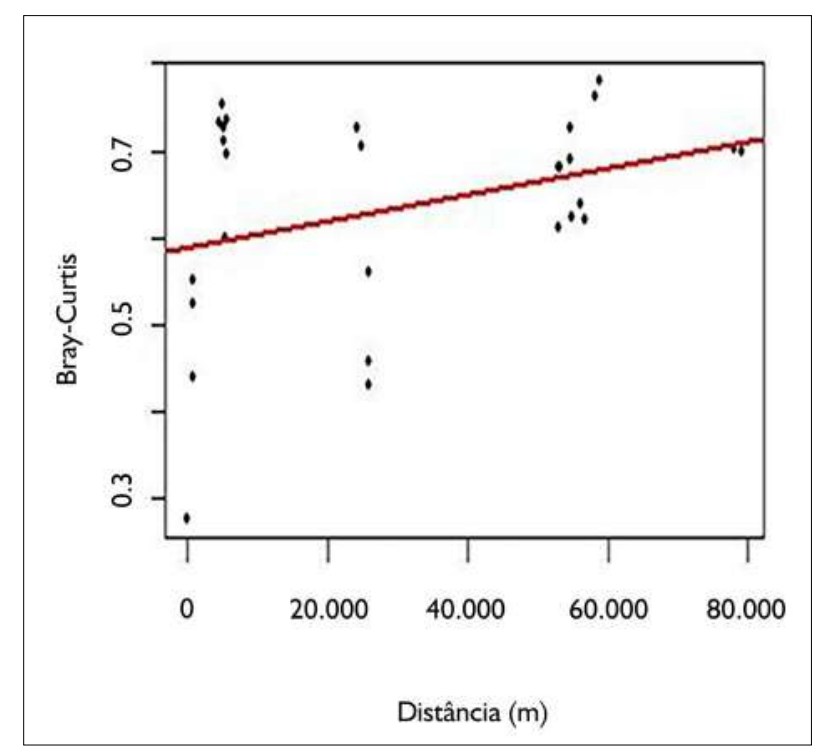

Figura 3. Correlograma de teste de Mantel, dissimilaridade (Bray-Curtis) das parcelas amostradas Submontana 1 NCR, Caraguatatuba, São Paulo; NPC 1, 2, 3 e 4, Ubatuba, São Paulo; Montana NCR 1, Caraguatatuba, São Paulo; e NSV 1 e 2, São Luís do Paraitinga, São Paulo. 
Neste caso, a espécie Mabea piriri Aubl. pode representar a expansão da população de espécies arbóreas na determinada área onde foi registrada com alto número de indivíduos no NCR Submontana 1. Quando se compara a outros trabalhos realizados em Mata Atlântica em mesma cota altitudinal, a espécie aparece com poucos indivíduos por parcela amostral. Isso se deve, provavelmente, ao fato de que a constatação destas espécies no NCR Submontana 1 foi na encosta da serra. Como destacado por Pscheidt \& Cordeiro (2012), áreas de encosta são o local onde a espécie aparece em maiores quantidades.

Este resultado pode estar relacionado à pouca antropização da área ou, até mesmo, à recuperação desta. Inclusive, é importante destacar que não foi catalogada nenhuma espécie exótica na área de estudo, o que reforça que Mabea piriri Aubl. é uma bioindicadora de ambiente em recuperação, destacando a importância da realização de estudos florísticos na Mata Atlântica, para que se possa conhecer o comportamento das espécies vegetais na floresta.

Essa necessidade está diretamente ligada às mudanças climáticas, que podem alterar as estruturas e florísticas dos biomas. Os fatores que causam extinção de espécies vêm sendo muito discutidos, por causarem mudanças evolutivas. Um dos fatores que influenciam nessas mudanças está relacionado com o aumento no estresse ambiental, como secas excessivas, que podem tender a limitar o crescimento das plantas e o desenvolvimento das florestas. Portanto, essas mudanças devem estar ligadas à tolerância e ao estresse que causam nas áreas florestais (Grime, 1977; Arendt, 1997; Fonseca et al., 2000; Tabarelli et al., 2014).

De acordo com McKinney \& Lockwood (1999), quando se tem a perda de algumas espécies que são 'chave' dentro de um bioma ou área florestal, ocorre consequentemente a expansão de outras espécies, e estas podem alterar toda a estrutura florestal. Essa constatação poderá causar alteração nas áreas, caso ocorram tais mudanças diante de fatores antrópicos, como o surgimento de espécies exóticas no PESM. Diante desses fatores, é importante destacar que as atividades antropogênicas sempre causam mudanças no ecossistema terrestre $(H$. Pereira et al., 2010), entre outras situações que levam a floresta ao declínio.

Mesmo com toda a influência antrópica que existe nas áreas do PESM, pode-se notar, com os resultados obtidos neste trabalho, que há grande ocorrência das principais espécies. Entre estas, pode-se citar Amaioua intermedia Mart., Bathysa australis (A. St.-Hil.) Benth. \& Hook. F., Bathysa mendoncaei K. Schum., Calyptranthes lucida Mart. Ex DC., Cabralea canjerana subsp. canjerana (Vell.) Mart., Chrysophyllum viride Mart. \& Eichler, Coussarea accedens Mull. Arg., Coussarea meridionalis var. porophylla (Vell.) Mull. Arg., Cryptocarya mandioccana Meisn, Euterpe edulis Mart., Faramea picinguabae M. Gomes, Inga capitata Desv., Myrciaria floribunda ( $\mathrm{H}$. West ex Willd.) O. Berg, Ocotea dispersa (Nees \& Mart.) Mez, Pouteria venosa (Mart.) Baehni, Syagrus pseudococos (Raddi) Glassman e Virola bicuhyba (Schott ex Spreng.) Warb., cujas presenças permitem a classificação da floresta como parte do grande hotspot da Mata Atlântica. As espécies citadas são encontradas em estudos de áreas florestais de alta diversidade na região da Mata Atlântica no PESM, evidenciando que as áreas são diversas e que há necessidade de preservação, para que a floresta continue em um bom estado de conservação, mantendo-se com altos índices de diversidade florística (Gandolfi et al., 1995; Medeiros, 2009; Gomes et al., 2011; Padgurschi et al., 2011; Rochelle et al., 2011).

As principais espécies de grande ocorrência neste trabalho são classificadas nas famílias arbóreas Myrtaceae, Lauraceae, Fabaceae, Sapotaceae, Euphorbiaceae, Rubiaceae, Meliaceae, Nyctaginaceae, Myristicaceae e Arecaceae, as quais também são as mais representativas em diversidade e riqueza em outros trabalhos realizados na Mata Atlântica (Gandolfi et al., 1995; Medeiros, 2009; Gomes et al., 2011; Padgurschi et al., 2011; Rochelle et al., 2011). Estas famílias têm a maior porção de indivíduos na menor classe de diâmetro, com distribuição que segue um exponencial 
negativo. Este é um fator típico de comunidade arbórea de floresta tropical (Gomes et al., 2011).

Dessa forma, é importante notar que as áreas amostradas neste trabalho no Núcleo Caraguatatuba possuem padrões muito comuns aos encontrados em diversas outras áreas de Mata Atlântica em geral (Medeiros, 2009; Padgurschi et al., 2011). Portanto, as mesmas têm uma dinâmica similar à da maior parte das áreas comparadas neste trabalho, por seguirem um padrão de alta biodiversidade, mesmo as que não possuem agrupamentos florísticos de espécies (Joly \& Martinelli, 2008; Eisenlohr et al., 2013).

As parcelas do NCR Submontana 1 e Montana 1, assim como algumas áreas do NPC Submontana 2 e NSV Montana 2, também passaram por processos ditos de antropização. Em meados de 1977, as áreas do NCR foram devastadas por uma catástrofe: uma tromba d'água fez com que grande parte da vegetação se perdesse por conta dos deslizamentos de terra, além da influência e presença da agricultura e da pecuária, praticadas em área próxima à região. $\mathrm{NPC}$ e NSV tiveram corte seletivo de madeira na década de 70 (Padgurschi et al., 2011). Ambos os processos contribuem para as variações estrutural e florística das áreas destacadas. Uma espécie como Euterpe edulis Mart. é indicadora de que estas áreas sofreram esses cortes, pois o baixo número de indivíduos desta espécie mostra claramente esse fator. Esta espécie tem grande importância para o ecossistema, sendo que, em locais preservados, a quantidade de indivíduos é sempre alta. Sua importância está ligada à sustentação das espécies animais que ajudam na dispersão de sementes para manutenção do equilíbrio desta planta na floresta (Marcos \& Matos, 2012). Portanto, sua preservação é necessária para garantir a conservação da Mata Atlântica.

Podemos aferir que, após esses processos, a Floresta Ombrófila Densa Atlântica das áreas amostrais ainda está em processo de regeneração (Joly \& Martinelli, 2008; Padgurschi et al., 2011; Tabarelli et al., 2014). Inclusive, foram identificadas espécies neste trabalho que indicam que a área está em estágio de regeneração natural, a exemplo da presença de Alchornea glandulosa Poepp, Brosimum guianense Huber, Cabralea canjerana (Vell.) Mart., Cariniana estrellensis (Raddi) Kuntze, Citronella paniculata (Mart.) R.A. Howard, Eugenia cerasiflora Miq., Euterpe edulis Mart., Guarea macrophyla Vahl, Guapira opposita (Vell.) Reitz, Hirtella hebeclada Moric. ex DC., Lamanonia ternata (Vel.), Matayba elaeagnoides Radlk. e Myrcia guianensis (Aubl.) DC., que também são registradas nos trabalhos de Garcia et al. (2011), Kunz \& Martins (2013) e Santos et al. (2018) como presentes em área de regeneração natural. Dessa forma, é essencial que trabalhos como estes ganhem reconhecimento, para que possam contribuir com a manutenção e a preservação principalmente de regiões que sofrem com a antropização.

Em relação aos resultados de similaridade e comparação entre as parcelas amostrais, provavelmente as diferenças encontradas no agrupamento por UPGMA, que definem uma maior similaridade entre algumas áreas ou distanciamento entre outras, estão ligadas às diferenças relacionadas à florística das áreas amostrais. Existe também uma correlação consistente entre elevação e temperatura, associando a altitude com variações de fisionomias que podem influenciar no agrupamento, mas que não foram testadas neste trabalho, por não haver dados coletados (Ivanauskas et al., 2000; Moreno et al., 2003; Eisenlohr et al., 2013; Sanchez et al., 2013).

Ao se discutir a similaridade das áreas NCR, NPC e NSV, foi usado o critério mais adotado na literatura e que reconhece apenas os grupos que possuem pelo menos $50 \%$ de similaridade. Diante desse contexto, há um grupo com três parcelas NPC Submontana 1, 2, 3 e 4 e as outras parcelas NCR e NSV estão isoladas, como se cada uma delas formasse um grupo.

A análise mostra que áreas mais próximas têm maior similaridade, o que pode ser visto com as espécies em comum entre Submontana 1 e Montana 1 do NCR. As espécies com maior quantidade de indivíduos e que ocorrem simultaneamente nestas parcelas são Alchornea gladulosa Poepp, Amaioua intermedia Mart., Bathysa australis 
(A. St.-Hil.) Benth. \& Hook. F., Bathysa mendoncaei K. Schum., Calyptranthes strigipes O. Berg, Cedrela fissilis Vell, Chrysophyllum viride Mart. \& Eichler, Couepia venosa Prance, Cryptocarya mandiocana Meisn, Cupania vernalis Cambess., Cyathea delgadii Sternb., Ecclinusa ramiflora Mart., Eriotheca pentaphylla (Vell. \& K. Schum.) A. Robyns, Eugenia batingabranca Sobral, Euterpe edulis Mart., Garcinia gardneriana (A.DC.) Radlk., Gomidesia spectabilis (DC.) O. Berg, Guapira hirsuta (Choisy) Lundell, Guapira opposita (Vell.) Reitz, Hirtella hebeclada Moric. ex DC., Marliera suaveolens Cambess., Mollinedia engleriana Pekins, Mollinedia uleana Perkins, Myrcia guianensis (Aubl.) DC., Myrcia ricardiana (O. Berg) Kiaersk., Myrciaria floribunda O. Berg, Neomitranthes glomerata D. Legrand, Ocotea dispersa (Nees \& Mart.), Ocotea elegans Mez, Psycotria vellosiana Benth. e Syagrus pseudococos (Raddi) Glassman. Essa similaridade entre as espécies de duas áreas de altitude diferente explica o agrupamento das parcelas.

Os resultados indicam que a migração de espécies pode estar ligada à proximidade geográfica das áreas, mesmo com altitudes distintas ou até mesmo por pertencerem naturalmente à plasticidade da espécie e se associarem à distribuição de forma menos restrita (Pilatti, 2018). Sendo assim, é necessário considerar que uma possível alteração climática poderá influenciar ainda mais estas similaridades.

Este fato pode estar relacionado com a grande diversidade que há na Mata Atlântica, afirmando existir similaridade florística entre áreas altitudinais diferentes, como nesse caso, com Submontana e Montana de mesma região no NCR. Contudo, é necessário que se atente aos fatores de semelhança florística entre as comunidades que foram analisadas, não associando o fator da semelhança de espécies apenas à proximidade geográfica destas áreas no NCR (Durigan et al., 2008). Dessa forma, leva-se em consideração também as diferenças entre os grupos, o que não exclui as ligações existentes entre eles, já que há uma variação na composição de espécies da Floresta Atlântica que provavelmente está ligada ao clima e a fatores espaciais
(Eisenlohr et al., 2013), afirmaç̧ão apoiada pela classificação e análise de ordenações feitas para as áreas deste trabalho.

Apesar disso, sugere-se que as variáveis ambientais e espaciais são significativamente correlacionadas aos padrões florísticos, deixando claro que a flora arbórea das florestas sazonais não deve mais ser considerada um subconjunto simples da flora da floresta tropical. Essa distribuição de espécies e a variância que ocorre entre as áreas da composição florística podem ser explicadas por fatores relacionados ao ambiente espacial, estruturado como vegetação Neotropical, além da grande relação com clima, topografia e força espacial, havendo, ainda, outros fatores ambientais relacionados, o que evidencia as diferenças encontradas nas comparações (Eisenlohr et al., 2013).

Os autores aferem alguns padrões fitogeográficos adicionais, reforçando que a Mata Atlântica, no entanto, abrange outros tipos de fisionomias, abrigando consequentemente uma grande variedade de espécies e famílias botânicas dentro das diferentes altitudes. Foi ressaltado por Eisenlohr et al. (2013) que essa grande abrangência é de extrema importância para a conservação deste hotspot de biodiversidade.

Destaca-se que existem formações de grupos distintos, isolados nas áreas avaliadas, principalmente pelo aumento da entropia das florestas, o que influencia na diminuição da heterogeneidade das espécies de cada parcela. Fatores como esses podem ser direcionados às perturbações antrópicas das áreas, além do declive e da superfície destas, o que também pode ajudar na compreensão dessa diferença de florística e segregação entre áreas (Eisenlohr et al., 2013).

Os padrões de vegetações e altitudes estão bem estabelecidos para a Mata Atlântica, no entanto, vários padrões diferentes têm sido observados (Eisenlohr et al., 2013). Assim, deve-se levar em consideração que ocorre sempre uma variação na composição das espécies ao longo de um gradiente, a qual ocorre em resposta às forças ambientais e espaciais (Eisenlohr et al., 2013), pois existem outros aspectos condicionantes à similaridade que podem indicar a diversidade florística da área. 
Em alguns trabalhos, foi discutido que existe uma tendência de variação na distribuição das espécies, quando há modificações na topografia das áreas (Guerra et al., 2013). Dessa forma, deve-se correlacionar os resultados obtidos nas áreas estudadas com esses trabalhos, devido principalmente aos grandes declives existentes na encosta da Serra do Mar.

É importante destacar também que as perturbações na floresta podem afetar os fatores ambientais, como a alteração da quantidade de água e a temperatura nessas áreas, considerados como os principais aspectos atenuantes da distribuição de vegetação (Holdridge, 1947; Gentry, 1988; Zhao et al., 2005; Eisenlohr et al., 2013). Além disso, destaque-se que a topografia afeta principalmente a riqueza de espécies em relação ao solo e à disponibilidade de água. Já em florestas com poucas variações sazonais climáticas, foi observada maior riqueza de espécies (Gentry, 1988; Pyke et al., 2001; Wolf et al., 2012; Eisenlohr et al., 2013).

Este trabalho de levantamento fitossociológico comparativo entre áreas contribui com a disponibilidade de dados acerca de levantamentos do Núcleo Caraguatatuba, que iniciou em 2010 e tem continuidade, nos anos subsequentes de monitoramento da Floresta Ombrófila Densa Atlântica, em outros trabalhos, a fim de verificar possíveis mudanças no funcionamento dessas áreas, as quais devem ser monitoradas em médio e longo prazo, principalmente em razão de as áreas do NCR serem regiões que poderão sofrer impactos e alterações na dinâmica da floresta, causados pelo funcionamento da Unidade de Tratamento de Gás de Caraguatatuba (UTGCA), através da possível deposição dos NOx, além de outros impactos diretos e indiretos ocorridos após o início do funcionamento da usina, com a expansão urbana. Fica evidente a necessidade de acompanhar por períodos espećíicos o desenvolvimento e o funcionamento das florestas estudadas, a fim de levantar questões e obter respostas ligadas às mudanças ambientais.

Este fator dá um alerta para os riscos que os processos antropogênicos causam às áreas florestais. É importante ressaltar que as florestas preservadas são responsáveis pelos serviços ecossistêmicos (Laurance et al., 2014; Wright, 2005). Tais mudanças ambientais causadas por fatores antrópicos podem tornar mais grave a situação, aumentando as alterações climáticas e a perda destes serviços ecossistêmicos, tão essenciais (Tabarelli et al., 2010).

Os resultados de diversos estudos, assim como os deste trabalho, contribuem ainda para mostrar quais são os impactos que o homem pode causar em estruturas florestais, ao evidenciarem que a influência direta do ser humano na natureza traz efeitos irreparáveis à flora e à fauna que compõem a floresta (Lovejoy et al., 1986; Whelam, 1995; Nascimento et al., 1999; Stern et al., 2002; Freitas et al., 2010), o que contribui para a descoberta de melhores caminhos e processos que convertam as mudanças climáticas atuais e subsequentes, influenciando de forma positiva todo o meio ambiente.

\section{AGRADECIMENTOS}

Este artigo é decorrente de projeto financiado pela Fundação de Amparo à Pesquisa do Estado de São Paulo (FAPESP), pela Coordenação de Aperfeiçoamento de Pessoal de Nível Superior (CAPES) e pelo Conselho Nacional de Desenvolvimento Científico e Tecnológico (CNPq) ao Instituto de Biologia, Departamento de Biologia Vegetal, da Universidade Estadual de Campinas (UNICAMP).

\section{REFERÊNCIAS}

Abbas, M. Z. M., Bruns, R. E., Scarminio, I. S., \& Ferreira, J. R. (1993). A multivariate statistical analysis of the composition of rainwater near Cubatão, SP, Brazil. Environmental Pollution, 79(3), 225233. https://doi.org/10.1016/0269-7491(93)90094-5

Alves, G., \& Marinho, M. M. O. (2015). Inventários urbanos de emissões de gases de efeito estufa no Brasil: uma análise preliminar. Encontro Empresarial de Gestão e Meio Ambiente - Engema. http:// engemausp.submissao.com.br/17/anais/arquivos/307.pdf

Andrade, D. C., \& Romeiro, A. R. (2009). Serviços ecossistêmicos e sua importância para o sistema econômico e o bem-estar humano. Texto para Discussão. IE/UNICAMP, (155), 1-43. http://www.avesmarinhas.com.br/Servi\%C3\%A7os\%20 e cossist $\%$ C $3 \%$ AAm i cos $\% 20$ e $\% 20$ sua $\% 20$ import\%C3\%A2ncia\%20econ\%C3\%B4mica.pdf 
Andrade, D. C., \& Romeiro, A. R. (2011). Degradação ambiental e teoria econômica: algumas reflexões sobre uma "Economia dos Ecossistemas". Revista EconomiA, 12(1), 3-26. https:// anpec.org.br/revista/vol12/vol12n1p3_26.pdf

Angiosperm Phylogeny Group (APG), 2016. An update of the Angiosperm Phylogeny Group classification for the orders and families of flowering plants: APG IV. Botanical Journal of the Linnean Society, 161(1), 105-121. https://doi.org/10.1111/boj.12385

Arendt, J. (1997). Adaptive intrinsic growth rates: an integration across taxa. Quarterly Review of Biology, 72(2), 149-177. https://www. jstor.org/stable/3036336

Artaxo, P., Oliveira, P. H., Lara, L. L., Pauliquevis, T. M., Rizzo, L. V., . . . . \& Correia, A. L. (2006). Efeitos climáticos de partículas de aerossóis biogênicos e emitidos em queimadas na Amazônia. Revista Brasileira de Meteorologia, 21(3a), 168-122. https://www.researchgate.net/publication/281269180_Efeitos climaticos_de_particulas_de_aerossois_biogenicos_e emitidos_em_queimadas_na_Ammazonia

Brasil, M. M. A. (2020). Ministério do Meio Ambiente. Bioma Mata Atlântica. https://www.mma.gov.br/biomas/mataatl\%C3\%A2ntica_emdesenvolvimento

Brower, J. E., \& Zar, J. H. (1984). Field and laboratory methods for general ecology. Wm. C. Brown Pub.

Bueno, M. L., Pennington, R. T., \& Dexter, K. G. (2017). Effects of Quaternary climatic fluctuations on the distribution of Neotropical savanna tree species. Ecography, 40(3), 403-414. http://doi.org/10.1111/ecog.01860

Butchart, S. H. M., Walpole, M., Collen, B., Strien, A. van, Scharlemann, J. P. W., Almond, R. E. A., \& Watson, R. (2010). Global biodiversity: indicators of recent declines. Science, 328(5982), 1164-1168. http://doi.org/10.1126/science.1187512

Campos, M. C. R. D., Tamashiro, J. Y., Assis, M. A., \& Joly, C. A. (2011). Florística e fitossociologia do componente arbóreo da transição floresta ombrófila densa das terras baixas-floresta ombrófila densa submontana do Núcleo Picinguaba/PESM, Ubatuba, sudeste do Brasil. Biota Neotropica, 11(2), 301-312. https://doi.org/10.1590/S1676-06032011000200030

Domingos, M., Lopes, M. I. M. S., \& Vuono, Y. S. (2000). Nutrient cycling disturbance in Atlantic Forest sites affected by air pollution coming from the industrial complex of Cubatão, Southeast Brazil. Brazilian Journal of Botany, 23(1), 77-85. https://doi.org/10.1590/S0100-84042000000100009

Durigan, G., Bernacci, L. C., Franco, G. A. D. C., Arbocz, G. D. F., Metzger, J. P., \& Catharino, E. L. M. (2008). Successional stage and geographic features determine floristic similarity among Atlantic Forest remnants, São Paulo State, Brazil. Acta Botanica Brasilica, 22(1), 51-62. https://doi.org/10.1590/S010233062008000100007
Eisenlohr, P. V., Alves, L. F., Bernacci, L. C., Padgurschi, M. C., Torres, R. B., Prata, E. M., \& Martins, F. R. (2013). Disturbances, elevation, topography and spatial proximity drive vegetation patterns along an altitudinal gradient of a top biodiversity hotspot. Biodiversity and Conservation, 22(12), 2767-2783. https://doi.org/10.1007/s10531-013-0553-x

Eisenlohr, P. V., \& Oliveira-Filho, T. (2015). Revisiting Patterns of Tree Species Composition and their Driving Forces in the Atlantic Forests of Southeastern Brazil. Biotropica, 47(6): 689-701. https://doi.org/10.1111/btp.12254

Fidalgo, O., \& Bononi, V. L. R. (1994). Técnicas de coleta, preservação e herborização de material botânico. Instituto de Botânica.

Fonseca, C. R., Overton, J. M., Collins, B., \& Westoby, M. (2000). Shifts in trait-combinations along rainfall and phosphorus gradients. Journal of Ecology, 88(6), 964-977. https://www. jstor.org/stable/2648405

Freitas, S. R., Longo, K. M., Silva Dias, M. A. F., \& Silva Dias, P. L. (2005). Emissões de queimadas em ecossistemas da América do Sul. Estudos Avançados, 19(53), 167-185. https://doi. org/10.1590/S0103-40142005000100011

Freitas, S. R., Hawbaker, T. J., \& Metzger, J. P. (2010). Effects of roads, topography, and land use on forest cover dynamics in the Brazilian Atlantic Forest. Forest Ecology and Management, 259(3), 410-417. https://doi.org/10.1016//.foreco.2009.10.036

Fundação S.O.S. Mata Atlântica (1992). Mata Atlântica. https://www. sosma.org.br/sobre/historia/

Gandolfi, S., Leitão Filho, H., \& Bezerra, C. L. F. (1995). Levantamento florístico e caráter sucessional das espécies arbustivo-arbóreas de uma Floresta Mesófila Semidecídua no município de Guarulhos, SP. Revista Brasileira de Biologia, 55(4), 753-767.

Garcia, C. C., Reis, M. D. G. F., Reis, G. G., Pezzopane, J. E. M., Lopes, H. N. S., \& Ramos, D. C. (2011). Regeneração natural de espécies arbóreas em fragmento de Floresta Estacional Semidecidual Montana, no domínio da Mata Atlântica, em Viçosa, MG. Ciência Florestal, 21(4), 677-688. https://doi. org/10.5902/198050984512

Gentry, A. H. (1988). Changes in plant community diversity and floristic composition on environmental and geographical gradients. Annals of the Missouri Botanical Garden, 75(1), 1-34 https://doi.org/10.2307/2399464

Gomes, J. A. M. A., Bernarcci, L. C., \& Joly, C. A. (2011). Diferenças florísticas e estruturais entre duas cotas altitudinais da Floresta Ombrófila Densa Submontana Atlântica, do Parque Estadual da Serra do Mar, município de Ubatuba/SP, Brasil. Biota Neotropica, 11(2), 123-137. https://doi.org/10.1590/S167606032011000200013 
Grime, J. P. (1977). Evidence for the existence of three primary strategies in plants and its relevance to ecological and evolutionary theory. The American Naturalist, 111(982), 11691194. https://www.jstor.org/stable/2460262

Guerra, T. N. F., Rodal, M. J. N., Lins e Silva, A. C. B., Alves, M., Silva, M. A. M., \& Mendes, P. G. A. (2013). Influence of edge and topography on the vegetation in an Atlantic Forest remnant in northeastern Brazil. Journal of Forest Research, 18(2), 200-208. https://doi.org/10.1007/s10310-012-0344-3

Hiura, A. L. (2011). Euphorbiaceae sensu stricto, Phyllanthaceae, Picrodendraceae e Putranjivaceae do campo experimental da EMBRAPA Amazônia oriental, município de Moju, Pará [Tese de doutorado, Universidade Federal Rural da Amazônia/Museu Paraense Emílio Goeldi, Belém].

Högberg, P. (2007). Nitrogen impacts on forest carbon. Nature, 447, 781-782. https://doi.org/10.1038/447781a

Holdridge, L. R. (1947). Determination of world plant formations from simple climatic data. Science, 105(2727), 367-368. http:// doi.org/10.1126/science.105.2727.367

Ivanauskas, N. M., Monteiro, R., \& Rodrigues, R. R. (2000). Similaridade florística entre áreas de Floresta Atlântica no estado de São Paulo. Brazilian Journal of Ecology, 1(2), 71-81.

Joly, C. A., \& Martinelli, L. A. (2008). Composição florística, estrutura e funcionamento da Floresta Ombrófila Densa dos Núcleos Picinguaba e Santa Virgínia do Parque Estadual da Serra do Mar, Estado de São Paulo, Brasil [3 Relatório do Projeto Temático Biota Gradiente Funcional]. São Paulo.

Joly, C. A., Metzger J. P., \& Tabarelli M. (2014). Experiences from the Brazilian Atlantic Forest: ecological findings and conservation initiatives. New Phytologist, 204(3), 459-473. https://doi. org/10.1111/nph.12989

Junior, L. R. N., Dompieri, M. H. G., \& Cruz, M. A. S. (2019). GeoTAB: Identificação dos biomas e da vegetação na região de atuação da Embrapa Tabuleiros Costeiros. Scientia Plena, 15(11), 1-20.

Klumpp, A., Klumpp, G., \& Domingos, M. (1994). Plants as bioindicators of air pollution at the Serra do Mar near the industrial complex of Cubatão, Brasil. Environmental Pollution, 85(1), 109-116. https://doi.org/10.1016/0269-7491(94)90244-5

Klumpp, A., Domingos, M., \& Klumpp, G. (1996). Assessment of the vegetation risk by fluoride emissions from fertiliser industries at Cubatão, Brazil. The Science of the Total Environment, 92(3), 219-228. https://doi.org/10.1016/S0048-9697(96)05298-9

Klumpp, A., Domingos, M., Moraes, R. M., \& Klumpp G. (1998). Effects of complex air pollution on tree species of the atlantic rain forest near Cubatão, Brasil. Chemosphere, 36(4-5), 989994. https://doi.org/10.1016/S0045-6535(97)10160-6
Köeppen, W. (1948). Climatologia. Fondo de Cultura Econômica.

Krug, T. (2008). Impacto, vulnerabilidade e adaptação das florestas à mudança climática. Parcerias Estratégicas, 13(27), 43-72. http://seer.cgee.org.br/index.php/parcerias_estrategicas/ article/view/332

Kunz, S. H., \& Martins, S. V. (2013). Regeneração natural de floresta estacional semidecidual em diferentes estágios sucessionais (Zona da Mata, MG, Brasil). Floresta, 44(1), 111-124. http:// dx.doi.org/10.5380/rf.v44i1.30736

Laurance, W. F., Sayer, J., \& Cassman, K. G. (2014). Agricultural expansion and its impacts on tropical nature. Trends in Ecology \& Evolution, 29(2), 107-116. https://doi.org/10.1016/j. tree.2013.12.001

Leitão Filho, H. F., Pagano, S. N., Cesar, O., Timoni, J. L., \& Rueda, J. J. (1993). Ecologia da Mata Atlântica em Cubatão. EdUNESP.

Lewis, S. L., Phillips, O. L., Baker, T. R., Lloyd, J., Malhi, Y., . . . \& Vinceti, B. (2004). Concerted changes in tropical forest structure and dynamics: evidence from 50 South American long-term plots. Philosophical Transactions of the Royal Society B, 359, 421-436. http://dx.doi.org/10.1098/rstb.2003.1431

Lovejoy, T. E., Bierregaard, R. O. Jr., Rylands, A. B., Malcolm, J. R., Quintela, C. E., Harper, L. H., Brown, K. S., Powell, A. H., Powell, G. V. N., Schubart, H. O. R., \& Hays, M. B. (1986). Edges and other effects of isolation on Amazon forest fragments. In M. E. Soulé (Ed.), Conservation biology: the science of scarcity and diversity (pp. 257-285). Sinauer.

Malhi, Y., Phillips, O. L., Lloyd, J., Baker, T., Wright . .., \& Vicenti, B. (2002). An international network to monitor the structure, composition and dynamics of Amazonian forests (RAINFOR). Journal of Vegetation Science, 13(3), 439-450. https://doi. org/10.1111/j.1654-1103.2002.tb02068.x

Marcos, C. S., \& Matos, D. M. S. (2012). Estrutura de populações de palmiteiro (Euterpe edulis Mart.) em áreas com diferentes graus de impactação na floresta da Tijuca, RJ. Floresta e Ambiente, 10(1), 27-37. https://floram.org/article/588e2201 e710ab87018b45ee

Martins, F. R. (1991). Estrutura de uma floresta mesófila. Editora da UNICAMP.

Martins, S. C. (2010). Caracterização dos solos e serrapilheira ao longo do gradiente altitudinal da Mata Atlântica, estado de São Paulo [Tese de doutorado, Universidade de São Paulo].

Mayer, R., Liess, S., Lopes, M. I. M. S., \& Kreutzer, K. 2000. Atmospheric pollution in a Tropical Rain Forest: effects of deposition upon biosphere and hydrosphere II. Fluxes of chemicals and element with budgets. Water, Air, and Soil Pollution, 121, 79-92. https://doi.org/10.1023/A:1005249615589 
Mckinney, M. L., \& Lockwood, J. L. (1999). Biotic homogenization: a few winners replacing many losers in the next mass extinction. Trends in Ecology and Evolution, 14(11), 450-453. https://doi. org/10.1016/S0169-5347(99)01679-1

Medeiros, M. C. M. P. (2009). Caracterização fitofisionômica e estrutural de áreas de Floresta Ombrófila Densa Montana do Parque Estadual da Serra do Mar, SP, Brasil [Dissertação de mestrado, Instituto de Botânica IBT/SMA, São Paulo, Brasil].

Moraes, R., Delitti, W. B. C., \& Moraes, J. A. P. V. D. (2000). Respostas de indivíduos jovens de Tibouchina pulchra Cogn. à poluição aérea de Cubatão, SP: fotossíntese líquida, crescimento e química foliar. Brazilian Journal of Botany, 23(4), 443-449. https://doi.org/10.1590/S0100-84042000000400010

Moreno, M. R., Nascimento, M. T., \& Kurtz, B. C. (2003). Estrutura e composição florística do estrato arbóreo em duas zonas altitudinais na Mata Atlântica de encosta da região de Imbé, RJ. Acta Botanica Brasilica, 17(3), 371-386. https://doi.org/10.1590/ S0102-33062003000300005

Mueller-Dombois, D., \& Ellenberg, H. (1974). Aims and methods for vegetation ecology. John Wiley \& Sons.

Myers, N., Mittermeier, R. A., Mittermeier, C. G., Da Fonseca, G. A., \& Kent, J. (2000). Biodiversity hotspots for conservation priorities. Nature, 403(6772), 853-858. https://doi.org/10.1038/35002501

Nascimento, H. E. M., Dias, A. S., Tabanez, A. A. J., \& Viana, V. M. (1999). Estrutura e dinâmica de populações arbóreas de um fragmento de floresta semidecidual na região de Piracicaba, SP. Revista Brasileira de Biologia, 59(2), 329-342. https://doi. org/10.1590/S0034-71081999000200015

Pachauri, R. K., \& Meyer, L. A. (Eds.). (2014). Mudança Climática 2014: Relatório de Síntese. Contribuição dos Grupos de Trabalho I, II e III para o Quinto Relatório de Avaliação do Painel Intergovernamental sobre Mudanças Climáticas. IPCC.

Padgurschi, M. D. C. G., Pereira, L. S., Tamashiro, J. Y., \& Joly, C. A. (2011). Composição e similaridade florística entre duas áreas de Floresta Atlântica Montana, São Paulo, Brasil. Biota Neotropica, 11(2), 139-152. https://doi.org/10.1590/S167606032011000200014

Pereira, H. M., Leadley, P. W., Proença, V., Alkemade, R., Scharlemann, J. P., Fernandez-Manjarrés, J. F., \& Chini, L. (2010). Scenarios for global biodiversity in the 21st century. Science, 330(6010), 1496-1501. http://doi.org/10.1126/ science. 1196624

Pereira, J. A. A., Oliveira-Filho, A. T., Eisenlohr, P. V., Miranda, P. L. S., \& Lemos Filho, J. P. (2015). Human impacts affect tree community features of 20 forest fragments of a vanishing Neotropical hotspot. Environmental Management, 55, 296307. https://doi.org/10.1007/s00267-014-0387-7
Pilatti, D. M. (2018). Ecological fitting em Schinus terebinthifolius Raddi: entendendo o processo de dispersão e invasão da espécie [Tese de doutorado, Universidade Federal do Paraná, Curitiba].

Pinheiro, E. S., \& Durigan, G. (2012). Diferenças florísticas e estruturais entre fitofisionomias do Cerrado em Assis, SP, Brasil. Revista Árvore, 36(1), 181-193. https://doi.org/10.1590/S010067622012000100019

Pscheidt, A. C., \& Cordeiro, I. (2012). Synopsis of the tribe Hippomaneae (Euphorbiaceae) in São Paulo State, Brazil. Hoehnea, 39(3), 347-368. https://doi.org/10.1590/S223689062012000300001

Pyke, C. R., Condit, R., Aguilar, S., \& Lao, S. (2001). Floristic composition across a climatic gradient in a neotropical lowland forest. Journal of Vegetation Science, 12(4), 553-566. https:// doi.org/10.2307/3237007

R Development Core Team. (2010). R: A Language and Environment for Statistical Computing. R Foundation for Statistical Computing.

Ramos, E., Torres, R. B., Veiga, R. F. D. A., \& Joly, C. A. (2011). Estudo do componente arbóreo de dois trechos da Floresta Ombrófila Densa Submontana em Ubatuba (SP). Biota Neotropica, 11(2), 313-335. https://doi.org/10.1590/S1676-06032011000200031

Ribeiro, K. T., \& Freitas, L. (2010). Impactos potenciais das alterações no Código Florestal sobre a vegetação de campos rupestres e campos de altitude. Biota Neotropica, 10(4), 239-246. https:// doi.org/10.1590/\$1676-06032010000400029

Rochelle, A. L. C., Cielo-Filho, R., \& Martins, F. R. (2011). Florística e estrutura de um trecho de Floresta Ombrófila Densa Atlântica Submontana no Parque Estadual da Serra do Mar, em Ubatuba/SP, Brasil. Biota Neotropica, 11(2), 337-346. https:// doi.org/10.1590/S1676-06032011000200032

Salati, E., Santos A. A., \& Klabi, I. (2006). Temas ambientais relevantes. Estudos Avançados, 20(56), 107-127. https://www. revistas.usp.br/eav/article/view/10125

Sanchez, M., Pedroni, F., Eisenlohr, P. V., \& Oliveira-Filho, A. T. (2013). Changes in tree community composition and structure of Atlantic rainforest on a slope of the Serra do Mar range, Southeastern Brazil, from near sea level to 1000 m of altitude. Flora - Morphology, Distribution, Functional Ecology of Plants, 208(3), 184-196. https://doi.org/10.1016/j.flora.2013.03.002

Santos, G. N. D., Higuchi, P., Silva, A. C. D., Farias, K. J., Machado, F. D., Duarte, E., \& Walter, F. F. (2018). Regeneração natural em uma Floresta com Araucária: inferências sobre o processo de construção da comunidade de espécies arbóreas. Ciência Florestal, 28(2), 483-494. https://doi. org/10.5902/1980509832029

Shepherd, G. J. (2010). FITOPAC 2.1. Manual do Usuário. Unicamp. 
Siche, R., Agostinho, F., Ortega, E., \& Romeiro, A. (2007). Índices versus indicadores: precisões conceituais na discussão da sustentabilidade de países. Ambiente \& Sociedade, 10(2), 137 148. https://doi.org/10.1590/S1414-753X2007000200009

Soares, S. R., Bernardes, R. S., \& Netto, O. M. (2002). Relações entre saneamento, saúde pública e meio ambiente: elementos para formulação de um modelo de planejamento em saneamento. Cadernos de Saúde Pública, 18(6), 1713-1724. https://doi.org/10.1590/S0102-311X2002000600026

Stefani, E. J. F. (2013). Estrutura, composição florística e similaridade entre áreas de Floresta Ombrófila Densa Submonta e Montana do Parque Estadual da Serra do Mar, litoral Nortel $S P$ [Dissertação de mestrado, Universidade Estadual de Campinas, Campinas].

Stern, M., Quesada, M., \& Stoner, K. E. (2002). Changes in composition and structure of a tropical dry forest following intermittent cattle grazing. Revista de Biología Tropical, 50(3-4), 1021-1034.

Stewart, G. R., Aidar, M. P. M., Joly, C. A., \& Schmidt, S. 2002. Impact of point source pollution on nitrogen isotope signatures $(\delta 15 \mathrm{~N})$ of vegetation in SE Brazil. Oecologia, 131, 468-472. https://doi. org/10.1007/s00442-002-0906-8

Tabarelli, M., Aguiar, A. V., Ribeiro, M. C., Metzger, J. P., \& Peres, C. A. (2010). Prospects for biodiversity conservation in the Atlantic Forest: lessons from aging human-modified landscapes. Biological Conservation, 143(10), 2328-2340. https://doi.org/10.1016/j. biocon.2010.02.005

Tabarelli, M., Leão, T. C., Fonseca, C. R., \& Peres, C. A. (2014). Predicting extinction risk of Brazilian Atlantic Forest angiosperms. Conservation Biology, 28(5), 1349-1359. https:// doi.org/10.1111/cobi.12286
Trindade, M. J. D. S. (2008). Euphorbiaceae Juss. da floresta nacional de Caxiuanã, com ênfase nas espécies ocorrentes na grade do PPBIO, Pará, Brasil [Tese de doutorado, Universidade Federal Rural da Amazônia/Museu Paraense Emílio Goeldi, Belém].

Uhlig, A., Goldemberg, J., \& Coelho, S. T. (2008). O uso de carvão vegetal na indústria siderúrgica brasileira e o impacto sobre as mudanças climáticas. Revista Brasileira de Energia, 14(2), 67-85. https://sbpe.org.br/index.php/rbe/article/view/224

Valentin, J. L. (2000). Ecologia numérica - uma introdução à análise multivariada de dados ecológicos. Interciência.

Veloso, H. P., Rangel-Filho, A. L. R., \& Lima, J. C. 1991. Classificação da vegetação brasileira adaptada a um sistema universal. IBGE.

Veneziani, Y., Cicco, V., Câmara, C. D., Ranzini, M., \& Arcova, F. C. S. (2009). Análise das precipitações e das vazões de um trecho da bacia hidrográfica do Rio Paraibuna-SP. IF Série Registros, (40), 197-202.

Whelam, R. J. (1995). The ecology of fire. Cambridge University Press.

Wright, S. J. (2005). Tropical forests in a changing environment. Trends in Ecology \& Evolution, 20(10), 553-560. https://doi. org/10.1016/j.tree.2005.07.009

Wolf, J. A., Fricker, G. A., Meyer, V., Hubbell, S. P., Gillespie, T. W., \& Saatchi, S. S. (2012). Plant species richness is associated with canopy height and topography in a neotropical. Remote Sensing, 4(12), 4010-4021. https://doi.org/10.3390/rs4124010

Zhao, C. M., Chen, W. L., Tian, Z. Q., \& Xie, Z. Q. (2005). Altitudinal pattern of plant species diversity in Shennongjia mountains, Central China. Journal of Integrative Plant Biology, 47(12), 1431 1449. https://doi.org/10.1111/.1744-7909.2005.00164.x

\section{CONTRIBUIÇÃO DOS AUTORES}

E. J. F. Stefani contribuiu com administração de projeto, análise formal, conceituação, curadoria de dados, escrita (rascunho original), investigação, metodologia, recursos, software, validação e visualização; J. Y. Tamashiro com conceituação, curadoria de dados, escrita (revisão e edição), metodologia, recursos, validação e visualização; e C. A. Joly com administração de projeto, aquisição de financiamento, conceituação, escrita (revisão e edição), metodologia, recursos, supervisão, validação e visualização.

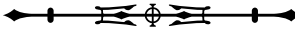


Apêndice 1. Espécies de árvores, 'palmeiras' e 'samambaias' arborescentes com as respectivas famílias. Indivíduos amostrados na fitofisionomia FOD Submontana em Caraguatatuba, São Paulo. Legendas: NInd = número de indivíduo; RelDe = densidade relativa; NAm = número de amostras; AbsDo = dominância absoluta; e IVI = índice de valor de importância. As espécies estão listadas em ordem de IVI.

(Continua)

\begin{tabular}{|c|c|c|c|c|c|c|}
\hline Espécies & Família & NInd & RelDe & NAm & AbsDo & IVI \\
\hline Mabea piriri Aubl. & Euphorbiaceae & 220 & 9,7 & 56 & 5,78 & 25,1 \\
\hline Bathysa mendoncaei K.Schum. & Rubiaceae & 116 & 5,11 & 54 & 1,28 & 11,1 \\
\hline Eriotheca pentaphylla (Vell. \& K.Schum.) A.Robyns & Malvaceae & 47 & 2,07 & 35 & 3 & 10,5 \\
\hline Actinostemon verticillatus (Klotzsch) Baill. & Euphorbiaceae & 90 & 3,97 & 40 & 1,57 & 9,72 \\
\hline Chrysophyllum viride Mart. \& Eichler & Sapotaceae & 25 & 1,1 & 20 & 2,51 & 7,52 \\
\hline Astrocaryum aculeatissimum (Schott) Burret & Arecaceae & 82 & 3,61 & 37 & 0,68 & 7,33 \\
\hline Euterpe edulis Mart. & Arecaceae & 73 & 3,22 & 38 & 0,73 & 7,11 \\
\hline Eugenia batingabranca Sobral & Myrtaceae & 55 & 2,42 & 34 & 0,92 & 6,46 \\
\hline Bathysa australis (A. St.-Hil.) Benth. \& Hook. f. & Rubiaceae & 50 & 2,2 & 36 & 0,76 & 6,03 \\
\hline Senefeldera multiflora (Mart.) Müll.Arg. & Euphorbiaceae & 45 & 1,98 & 25 & 1,07 & 5,75 \\
\hline Albizia pedicellaris (DC.) L.Rico & Fabaceae & 20 & 0,88 & 12 & 1,99 & 5,74 \\
\hline Mollinedia pachysandra Perkins & Monimiaceae & 25 & 1,1 & 21 & 1,4 & 5,31 \\
\hline Sloanea monosperma Vell. & Elaeocarpaceae & 28 & 1,23 & 22 & 1,28 & 5,26 \\
\hline Guapira opposita (Vell.) Reitz & Nyctaginaceae & 28 & 1,23 & 16 & 1,12 & 4,54 \\
\hline Gomidesia spectabilis (DC.) O.Berg & Myrtaceae & 39 & 1,72 & 27 & 0,43 & 4,3 \\
\hline Faramea picinguabae M. Gomes & Rubiaceae & 39 & 1,72 & 30 & 0,2 & 4,01 \\
\hline Ocotea aff. estrellense Mez & Lauraceae & 20 & 0,88 & 19 & 0,91 & 3,95 \\
\hline Coussarea meridionalis var. porophylla (Vell.) Müll. Arg. & Rubiaceae & 35 & 1,54 & 26 & 0,34 & 3,88 \\
\hline Actinostemon sp.1 & Euphorbiaceae & 31 & 1,37 & 23 & 0,44 & 3,71 \\
\hline Coussarea accedens Müll.Arg. & Rubiaceae & 35 & 1,54 & 24 & 0,19 & 3,44 \\
\hline Pseudopiptadenia warmingii (Benth.) G.P.Lewis & Fabaceae & 6 & 0,26 & 6 & 1,08 & 2,88 \\
\hline Brosimum guianense (Aubl.) Huber & Moraceae & 20 & 0,88 & 19 & 0,38 & 2,86 \\
\hline Brosimum lactescens (S.Moore) C.C.Berg & Moraceae & 17 & 0,75 & 15 & 0,55 & 2,83 \\
\hline Calyptranthes lucida Mart. ex DC. & Myrtaceae & 21 & 0,93 & 13 & 0,53 & 2,83 \\
\hline Lacistema lucidum Schnizl. & Lacistemataceae & 23 & 1,01 & 17 & 0,35 & 2,8 \\
\hline Mollinedia engleriana Perkins & Monimiaceae & 25 & 1,1 & 21 & 0,17 & 2,77 \\
\hline Tabebuia cassinoides (Lam.) DC. & Bignoniaceae & 16 & 0,71 & 12 & 0,59 & 2,67 \\
\hline Cryptocarya mandioccana Meisn. & Lauraceae & 14 & 0,62 & 13 & 0,59 & 2,65 \\
\hline Eugenia cuprea (O. Berg) Mattos & Myrtaceae & 21 & 0,93 & 17 & 0,29 & 2,6 \\
\hline Matayba guianensis Aubl. & Sapindaceae & 24 & 1,06 & 18 & 0,18 & 2,55 \\
\hline Myrciaria floribunda (H.West ex Willd.) O.Berg & Myrtaceae & 22 & 0,97 & 20 & 0,13 & 2,5 \\
\hline Syagrus pseudococos (Raddi) Glassman & Arecaceae & 19 & 0,84 & 14 & 0,34 & 2,41 \\
\hline Zygia latifolia var. glabrata (Mart.) Barneby \& J.W.Grimes & Fabaceae & 22 & 0,97 & 19 & 0,08 & 2,33 \\
\hline Alchornea glandulosa Poepp & Euphorbiaceae & 17 & 0,75 & 15 & 0,31 & 2,32 \\
\hline Hieronyma alchorneoides Allemão & Phyllanthaceae & 18 & 0,79 & 15 & 0,28 & 2,31 \\
\hline Tapirira guianensis Engl. & Anacardiaceae & 11 & 0,48 & 11 & 0,54 & 2,28 \\
\hline Guapira hirsuta (Choisy) Lundell & Nyctaginaceae & 19 & 0,84 & 16 & 0,19 & 2,22 \\
\hline
\end{tabular}


Apêndice 1.

(Continua)

\begin{tabular}{|c|c|c|c|c|c|c|}
\hline Espécies & Família & NInd & RelDe & NAm & AbsDo & IVI \\
\hline Neomitranthes glomerata (D.Legrand) D.Legrand & Myrtaceae & 17 & 0,75 & 16 & 0,21 & 2,18 \\
\hline Sorocea hilarii Gaudich. & Moraceae & 15 & 0,66 & 14 & 0,29 & 2,14 \\
\hline Pera glabrata (Schott) Poepp. ex Baill. & Peraceae & 16 & 0,71 & 12 & 0,3 & 2,08 \\
\hline Amaioua intermedia Mart. & Rubiaceae & 17 & 0,75 & 12 & 0,26 & 2,03 \\
\hline Cedrela fissilis Vell. & Meliaceae & 7 & 0,31 & 7 & 0,61 & 2,01 \\
\hline Ecclinusa ramiflora Mart. & Sapotaceae & 17 & 0,75 & 14 & 0,18 & 1,99 \\
\hline Myrcia guianensis (Aubl.) DC. & Myrtaceae & 17 & 0,75 & 15 & 0,14 & 1,97 \\
\hline Ocotea argentea Mez & Lauraceae & 14 & 0,62 & 13 & 0,25 & 1,95 \\
\hline Dictyoloma vandellianum A. Juss. & Rutaceae & 11 & 0,48 & 7 & 0,49 & 1,93 \\
\hline Pourouma guianensis Aubl. & Urticaceae & 13 & 0,57 & 12 & 0,27 & 1,88 \\
\hline Calyptranthes grandifolia O.-Berg & Myrtaceae & 12 & 0,53 & 12 & 0,27 & 1,84 \\
\hline Hirtella hebeclada Moric. ex DC. & Chrysobalanaceae & 13 & 0,57 & 12 & 0,23 & 1,8 \\
\hline Trichilia silvatica C.DC. & Meliaceae & 7 & 0,31 & 4 & 0,58 & 1,76 \\
\hline Virola gardneri (A.DC.) Warb. & Myristicaceae & 8 & 0,35 & 6 & 0,49 & 1,75 \\
\hline Myrcia richardiana (O.Berg) Kiaersk. & Myrtaceae & 15 & 0,66 & 11 & 0,15 & 1,67 \\
\hline Ocotea elegans Mez & Lauraceae & 13 & 0,57 & 10 & 0,21 & 1,63 \\
\hline Miconia dodecandra Cogn. & Melastomataceae & 15 & 0,66 & 10 & 0,14 & 1,57 \\
\hline Pouteria caimito (Ruiz \& Pav.) Radlk. & Sapotaceae & 10 & 0,44 & 8 & 0,3 & 1,56 \\
\hline Psychotria vellosiana Benth. & Rubiaceae & 14 & 0,62 & 13 & 0,05 & 1,52 \\
\hline Casearia arborea (Rich.) Urb. & Salicaceae & 10 & 0,44 & 10 & 0,2 & 1,47 \\
\hline Cupania vernalis Cambess. & Sapindaceae & 10 & 0,44 & 10 & 0,16 & 1,4 \\
\hline Mollinedia uleana Perkins & Monimiaceae & 6 & 0,26 & 6 & 0,36 & 1,38 \\
\hline Pausandra morisiana (Casar.) Radlk. & Euphorbiaceae & 12 & 0,53 & 10 & 0,08 & 1,32 \\
\hline Ocotea venulosa (Nees) Baitello & Lauraceae & 10 & 0,44 & 9 & 0,15 & 1,31 \\
\hline Actinostemon klotzschii (Didr.) Pax. & Euphorbiaceae & 7 & 0,31 & 6 & 0,29 & 1,29 \\
\hline Cordia taguahyensis Vell. & Boraginaceae & 9 & 0,4 & 9 & 0,16 & 1,29 \\
\hline Licaria armeniaca (Nees) Kosterm. & Lauraceae & 11 & 0,48 & 8 & 0,15 & 1,29 \\
\hline Myrcia amazonica DC. & Myrtaceae & 10 & 0,44 & 10 & 0,11 & 1,29 \\
\hline Licania hoehnei Pilg. & Chrysobalanaceae & 10 & 0,44 & 9 & 0,11 & 1,23 \\
\hline Garcinia gardneriana (Planch \& Triana) Zappi & Clusiaceae & 10 & 0,44 & 9 & 0,1 & 1,21 \\
\hline Malouetia arborea (Vell.) Miers & Apocynaceae & 8 & 0,35 & 8 & 0,17 & 1,21 \\
\hline Marlierea suaveolens Cambess. & Myrtaceae & 10 & 0,44 & 10 & 0,07 & 1,2 \\
\hline Ocotea dispersa (Nees \& Mart.) Mez & Lauraceae & 10 & 0,44 & 9 & 0,09 & 1,19 \\
\hline Pouteria oxypetala T.D.Penn. & Sapotaceae & 8 & 0,35 & 7 & 0,19 & 1,19 \\
\hline Nectandra membranacea (Sw.) Griseb. & Lauraceae & 6 & 0,26 & 6 & 0,26 & 1,17 \\
\hline Cabralea canjerana (Vell.) Mart. & Meliaceae & 4 & 0,18 & 4 & 0,36 & 1,16 \\
\hline Cyathea corcovadensis (Raddi) Domin & Cyatheaceae & 10 & 0,44 & 8 & 0,05 & 1,05 \\
\hline Myrceugenia myrcioides (Cambess.) O.Berg & Myrtaceae & 9 & 0,4 & 8 & 0,07 & 1,04 \\
\hline Savia dictyocarpa Müll.Arg. & Phyllanthaceae & 7 & 0,31 & 6 & 0,15 & 1 \\
\hline Vochysia bifalcata Warm. & Vochysiaceae & 3 & 0,13 & 3 & 0,33 & 1 \\
\hline
\end{tabular}


Apêndice 1.

(Continua)

\begin{tabular}{|c|c|c|c|c|c|c|}
\hline Espécies & Família & NInd & RelDe & NAm & AbsDo & IVI \\
\hline Guapira of. venosa (Choisy) Lundell & Nyctaginaceae & 8 & 0,35 & 8 & 0,04 & 0,95 \\
\hline Virola bicuhyba (Schott ex Spreng.) Warb. & Myristicaceae & 8 & 0,35 & 7 & 0,08 & 0,95 \\
\hline Actinostemon concolor (Spreng.) Müll.Arg. & Euphorbiaceae & 10 & 0,44 & 7 & 0,03 & 0,94 \\
\hline Licania octandra (Hoffmanns. ex Roem. \& Schult Kuntze & Chrysobalanaceae & 7 & 0,31 & 7 & 0,07 & 0,9 \\
\hline Tabebuia serratifolia (Vahl) G.Nicholson & Bignoniaceae & 6 & 0,26 & 6 & 0,12 & 0,9 \\
\hline Couepia venosa Prance & Chrysobalanaceae & 6 & 0,26 & 6 & 0,11 & 0,86 \\
\hline Nectandra cissiflora Nees & Lauraceae & 6 & 0,26 & 4 & 0,16 & 0,84 \\
\hline Myrcia splendens (Sw.) DC. & Myrtaceae & 7 & 0,31 & 5 & 0,1 & 0,83 \\
\hline Maytenus robusta Reissek & Celastraceae & 7 & 0,31 & 6 & 0,06 & 0,81 \\
\hline Psychotria nuda (Cham. \& Schltdl.) Wawra & Rubiaceae & 8 & 0,35 & 6 & 0,04 & 0,81 \\
\hline Cryptocarya saligna Mez & Lauraceae & 5 & 0,22 & 5 & 0,13 & 0,8 \\
\hline Aparisthmium cordatum (A.Juss.) Baill. & Euphorbiaceae & 6 & 0,26 & 6 & 0,07 & 0,79 \\
\hline Cariniana legalis (Mart.) Kuntze & Lecythidaceae & 4 & 0,18 & 4 & 0,17 & 0,78 \\
\hline Guatteria hilariana Engl. & Annonaceae & 6 & 0,26 & 6 & 0,06 & 0,75 \\
\hline Ocotea odorifera (Vell.) Rohwer & Lauraceae & 4 & 0,18 & 4 & 0,15 & 0,74 \\
\hline Terminalia cf. januariensis DC. & Combretaceae & 4 & 0,18 & 4 & 0,15 & 0,74 \\
\hline Heisteria silvianii Schwacke & Olacaceae & 6 & 0,26 & 6 & 0,04 & 0,73 \\
\hline Tachigali multijuga Benth. & Fabaceae & 4 & 0,18 & 4 & 0,14 & 0,72 \\
\hline Calyptranthes sp. & Myrtaceae & 6 & 0,26 & 5 & 0,05 & 0,68 \\
\hline Pouteria venosa (Mart.) Baehni & Sapotaceae & 5 & 0,22 & 5 & 0,06 & 0,65 \\
\hline Copaifera langsdorffii Desf. & Fabaceae & 4 & 0,18 & 4 & 0,1 & 0,63 \\
\hline Faramea pachyantha Müll. Arg. & Rubiaceae & 5 & 0,22 & 5 & 0,04 & 0,62 \\
\hline Mollinedia schottiana (Spreng.) Perkins & Monimiaceae & 5 & 0,22 & 5 & 0,04 & 0,62 \\
\hline Pouteria hispida Eyma & Sapotaceae & 5 & 0,22 & 5 & 0,04 & 0,62 \\
\hline Schefflera angustissima (Marchal) Frodin & Araliaceae & 5 & 0,22 & 4 & 0,07 & 0,61 \\
\hline Ficus gomelleira Kunth \& C.D.Bouché & Moraceae & 3 & 0,13 & 3 & 0,14 & 0,6 \\
\hline Matayba juglandifolia Radlk. & Sapindaceae & 5 & 0,18 & 5 & 0,08 & 0,6 \\
\hline Alchornea triplinervia (Spreng.) Müll.Arg. & Euphorbiaceae & 4 & 0,18 & 4 & 0,08 & 0,59 \\
\hline Pouteria psammophila (Mart.) Radlk. & Sapotaceae & 4 & 0,18 & 4 & 0,08 & 0,58 \\
\hline Marlierea tomentosa Cambess. & Myrtaceae & 5 & 0,22 & 5 & 0,02 & 0,57 \\
\hline Symplocos estrellensis Casar. & Symplocaceae & 4 & 0,18 & 4 & 0,07 & 0,57 \\
\hline Ilex theezans Mart. & Aquifoliaceae & 3 & 0,13 & 3 & 0,11 & 0,56 \\
\hline Inga striata Benth. & Fabaceae & 3 & 0,13 & 3 & 0,12 & 0,56 \\
\hline Myrtaceae sp.3 & Myrtaceae & 4 & 0,18 & 3 & 0,09 & 0,55 \\
\hline Eugenia oblongata $\bigcirc$. Berg & Myrtaceae & 5 & 0,22 & 4 & 0,03 & 0,54 \\
\hline Pouteria gardneriana (A.DC.) Radlk. & Sapotaceae & 3 & 0,13 & 3 & 0,1 & 0,52 \\
\hline Campomanesia guaviroba (DC.) Kiaersk. & Myrtaceae & 4 & 0,18 & 4 & 0,04 & 0,5 \\
\hline Schoepfia brasiliensis A.DC. & Schoepfiaceae & 4 & 0,18 & 4 & 0,03 & 0,5 \\
\hline Aniba firmula (Nees \& Mart.) Mez & Lauraceae & 4 & 0,18 & 4 & 0,03 & 0,49 \\
\hline Calyptranthes strigipes O. Berg & Myrtaceae & 3 & 0,13 & 3 & 0,08 & 0,48 \\
\hline
\end{tabular}


Apêndice 1.

(Continua)

\begin{tabular}{|c|c|c|c|c|c|c|}
\hline Espécies & Família & NInd & RelDe & $\mathrm{NAm}$ & AbsDo & IVI \\
\hline Myrtaceae sp.1 & Myrtaceae & 4 & 0,18 & 4 & 0,03 & 0,48 \\
\hline Inga capitata Desv. & Fabaceae & 4 & 0,18 & 4 & 0,02 & 0,47 \\
\hline Licania reticulata Prance & Chrysobalanaceae & 4 & 0,18 & 4 & 0,02 & 0,47 \\
\hline Ocotea brachrybotra (Meisn.) Mez & Lauraceae & 4 & 0,18 & 4 & 0,02 & 0,47 \\
\hline Rudgea vellerea Mull.Arg. & Rubiaceae & 4 & 0,18 & 4 & 0,02 & 0,46 \\
\hline Abarema turbinata (Benth.) Barneby \& J.W.Grimes & Fabaceae & 2 & 0,09 & 2 & 0,11 & 0,44 \\
\hline Hymenolobium janeirense Kuhlm. & Fabaceae & 4 & 0,18 & 3 & 0,04 & 0,44 \\
\hline Roupala brasiliensis Klotzsch & Proteaceae & 3 & 0,13 & 3 & 0,06 & 0,44 \\
\hline Jacaranda puberula Cham. & Bignoniaceae & 3 & 0,13 & 3 & 0,05 & 0,42 \\
\hline Maytenus schumanniana Loes. & Celastraceae & 3 & 0,13 & 3 & 0,05 & 0,41 \\
\hline Cyathea delgadii Sternb. & Cyatheaceae & 6 & 0,26 & 1 & 0,03 & 0,4 \\
\hline Ocotea aciphylla (Nees \& Mart.) Mez & Lauraceae & 2 & 0,09 & 2 & 0,09 & 0,4 \\
\hline Tontelea leptophylla A.C.Sm. & Celastraceae & 3 & 0,13 & 3 & 0,03 & 0,39 \\
\hline Chrysophyllum flexuosum Mart. & Sapotaceae & 3 & 0,13 & 3 & 0,01 & 0,35 \\
\hline Eugenia cerasiflora Miq. & Myrtaceae & 3 & 0,13 & 3 & 0,01 & 0,34 \\
\hline Mollinedia utriculatus (Mart.) Perkins & Monimiaceae & 3 & 0,13 & 3 & 0,01 & 0,34 \\
\hline Urbanodendron bahiense (Meisn.) Rohwer & Lauraceae & 2 & 0,09 & 2 & 0,06 & 0,34 \\
\hline Dendropanax monogynus (Vell.) Seem. & Araliaceae & 3 & 0,13 & 3 & 0,01 & 0,33 \\
\hline Lamanonia ternata Vell. & Cunoniaceae & 1 & 0,04 & 1 & 0,1 & 0,31 \\
\hline Sapium glandulatum (Vell.) Pax & Euphorbiaceae & 1 & 0,04 & 1 & 0,1 & 0,31 \\
\hline Rapanea venosa (A. DC.) Mez & Primulaceae & 2 & 0,09 & 2 & 0,04 & 0,3 \\
\hline Cupania oblongifolia Mart. & Sapindaceae & 2 & 0,09 & 2 & 0,04 & 0,29 \\
\hline Ardisia martiana Miq. & Primulaceae & 3 & 0,13 & 2 & 0,01 & 0,28 \\
\hline Licania kunthiana Hook. f. & Chrysobalanaceae & 3 & 0,13 & 2 & 0,01 & 0,28 \\
\hline Calophyllum brasiliensis Cambess. & Clusiaceae & 2 & 0,09 & 2 & 0,03 & 0,27 \\
\hline Cordia sellowiana Cham. & Boraginaceae & 2 & 0,09 & 2 & 0,02 & 0,26 \\
\hline Myrtaceae sp.2 & Myrtaceae & 2 & 0,09 & 2 & 0,02 & 0,26 \\
\hline Chrysophyllum dusenii Cronquist & Sapotaceae & 2 & 0,09 & 2 & 0,02 & 0,25 \\
\hline Cariniana estrellensis (Raddi) Kuntze & Lecythidaceae & 2 & 0,09 & 2 & 0,01 & 0,24 \\
\hline Citronella paniculata (Mart.) R.A. Howard & Cardiopteridaceae & 2 & 0,09 & 2 & 0,01 & 0,23 \\
\hline Conchocarpus fontanesianus (A. St.-Hil.) Kallunki \& Piran & Rutaceae & 2 & 0,09 & 2 & 0,01 & 0,23 \\
\hline Cupania concolor Radlk. & Sapindaceae & 2 & 0,09 & 2 & 0,01 & 0,23 \\
\hline Eugenia prasina $\bigcirc$. Berg & Myrtaceae & 2 & 0,09 & 2 & 0,01 & 0,23 \\
\hline Miconia brasiliensis (Spreng.) Triana & Melastomataceae & 2 & 0,09 & 2 & 0,01 & 0,23 \\
\hline Mollinedia blumenaviana Perkins & Monimiaceae & 2 & 0,09 & 2 & 0,01 & 0,23 \\
\hline Salacia grandifolia (Mart. ex Schult.) G.Don & Celastraceae & 2 & 0,09 & 2 & 0,01 & 0,23 \\
\hline Stifftia fruticosa (Vell.) D.J.N.Hind \& Semir & Compositae & 2 & 0,09 & 2 & 0 & 0,22 \\
\hline Hymenaea courbaril L. & Fabaceae & 1 & 0,04 & 1 & 0,05 & 0,21 \\
\hline Prunus myrtifolia (L.) Urb. & Rosaceae & 1 & 0,04 & 1 & 0,05 & 0,2 \\
\hline Eugenia sp.2 & Myrtaceae & 1 & 0,04 & 1 & 0,04 & 0,19 \\
\hline
\end{tabular}


Apêndice 1.

(Conclusão)

\begin{tabular}{|c|c|c|c|c|c|c|}
\hline Espécies & Família & NInd & RelDe & NAm & AbsDo & IVI \\
\hline Copaifera trapezifolia Hayne & Fabaceae & 1 & 0,04 & 1 & 0,04 & 0,18 \\
\hline Jacaratia spinosa (Aubl.) A.DC. & Caricaceae & 1 & 0,04 & 1 & 0,03 & 0,17 \\
\hline Eugenia sp.1 & Myrtaceae & 1 & 0,04 & 1 & 0,03 & 0,16 \\
\hline Solanum pseudoquina A. St.-Hil. & Solanaceae & 2 & 0,09 & 1 & 0,01 & 0,16 \\
\hline Hippocratea comosa Sw. & Celastraceae & 1 & 0,04 & 1 & 0,02 & 0,15 \\
\hline Solanum rufescens Sendtn. & Solanaceae & 1 & 0,04 & 1 & 0,02 & 0,14 \\
\hline Buchenavia kleinii Exell & Combretaceae & 1 & 0,04 & 1 & 0,01 & 0,13 \\
\hline Ficus insipida Willd. & Moraceae & 1 & 0,04 & 1 & 0,01 & 0,13 \\
\hline Samanea sp. & Fabaceae & 1 & 0,04 & 1 & 0,01 & 0,13 \\
\hline Allophylus petiolulatus Radlk. & Sapindaceae & 1 & 0,04 & 1 & 0,01 & 0,12 \\
\hline Byrsonima intermedia A. Juss. & Malpighiaceae & 1 & 0,04 & 1 & 0,01 & 0,12 \\
\hline Citronella megaphylla R.A. Howard & Cardiopteridaceae & 1 & 0,04 & 1 & 0 & 0,12 \\
\hline Clethra scabra Pers. & Clethraceae & 1 & 0,04 & 1 & 0,01 & 0,12 \\
\hline Maytenus communis Reissek & Celastraceae & 1 & 0,04 & 1 & 0,01 & 0,12 \\
\hline Miconia budljoides Triana & Melastomataceae & 1 & 0,04 & 1 & 0,01 & 0,12 \\
\hline Myrcia tijucensis Kiaersk. & Myrtaceae & 1 & 0,04 & 1 & 0 & 0,12 \\
\hline Vernonanthura discolor (Spreng.) H.Rob. & Compositae & 1 & 0,04 & 1 & 0,01 & 0,12 \\
\hline Zollernia ilicifolia (Brongn.) Vogel & Fabaceae & 1 & 0,04 & 1 & 0,01 & 0,12 \\
\hline Andira fraxinifolium Benth. & Fabaceae & 1 & 0,04 & 1 & 0 & 0,11 \\
\hline Chomelia bella (Standl.) Steyerm. & Rubiaceae & 1 & 0,04 & 1 & 0 & 0,11 \\
\hline Dilodendron bipinnatum Radlk. & Sapindaceae & 1 & 0,04 & 1 & 0 & 0,11 \\
\hline Erythroxylum speciosum O.E.Schulz & Erythroxylaceae & 1 & 0,04 & 1 & 0 & 0,11 \\
\hline Guarea macrophylla Vahl & Meliaceae & 1 & 0,04 & 1 & 0 & 0,11 \\
\hline Matayba intermedia Mart. & Sapindaceae & 1 & 0,04 & 1 & 0 & 0,11 \\
\hline Miconia petropolitana Cogn. & Melastomataceae & 1 & 0,04 & 1 & 0 & 0,11 \\
\hline Terminalia of. argentea Mart. & Combretaceae & 1 & 0,04 & 1 & 0 & 0,11 \\
\hline Total & & 2182 & 96,00 & 1538 & 46,96 & 289,00 \\
\hline
\end{tabular}


Apêndice 2. Espécies de árvores, 'palmeiras' e 'samambaias' com as respectivas famílias. Indivíduos amostrados na fitofisionomia FOD NCR Montana 1 em Caraguatatuba, São Paulo. Legendas: NInd = número de indivíduo; RelDe = densidade relativa; NAm = número de amostras; $\mathrm{AbsDo}=$ dominância absoluta; e IVI = índice de valor de importância.

(Continua)

\begin{tabular}{|c|c|c|c|c|c|c|}
\hline Espécies & Família & NInd & RelDe & NAm & AbsDo & $\mathrm{IVI}$ \\
\hline Chrysophyllum viride Mart. \& Eichler & Sapotaceae & 60 & 3,14 & 39 & 8,78 & 24,62 \\
\hline Euterpe edulis Mart. & Arecaceae & 186 & 9,74 & 79 & 0,64 & 16,53 \\
\hline Guapira venosa (Choisy) Lundell & Nyctaginaceae & 56 & 2,93 & 32 & 1,12 & 7,52 \\
\hline Guapira opposita (Vell.) Reitz & Nyctaginaceae & 52 & 2,72 & 36 & 0,89 & 7,09 \\
\hline Mollinedia pachysandra Pekins & Monimiaceae & 38 & 1,99 & 28 & 1,45 & 7,03 \\
\hline Eriotheca pentaphylla (Vell. \& K. Schum.) A. Robyns & Malvaceae & 42 & 2,2 & 26 & 1,34 & 6,86 \\
\hline Guapira hirsuta (Choisy) Lundell & Nyctaginaceae & 60 & 3,14 & 35 & 0,61 & 6,85 \\
\hline Alchornea glandulosa Poepp & Euphorbiaceae & 19 & 1 & 17 & 2,17 & 6,8 \\
\hline Myrcia tijucensis Kiaersk. & Myrtaceae & 36 & 1,89 & 27 & 1,03 & 5,95 \\
\hline Mollinedia blumenaviana Perkins & Monimiaceae & 46 & 2,41 & 31 & 0,33 & 5,23 \\
\hline Eugenia batingabranca Sobral & Myrtaceae & 42 & 2,2 & 32 & 0,38 & 5,22 \\
\hline Schefflera angustissima (Marchal) Frodin & Araliaceae & 23 & 1,2 & 22 & 1,04 & 4,95 \\
\hline Bathysa australis (A. St. -Hil.) Benth. \& Hook. F. & Rubiaceae & 36 & 1,89 & 23 & 0,6 & 4,75 \\
\hline Marlierea suaveolens Cambess. & Myrtaceae & 39 & 2,04 & 31 & 0,23 & 4,67 \\
\hline Myrcia guianensis (Aubl.) DC. & Myrtaceae & 32 & 1,68 & 27 & 0,48 & 4,55 \\
\hline Garcinia gardneriana (Planch \& Triana) Zappi & Clusiaceae & 33 & 1,73 & 30 & 0,32 & 4,47 \\
\hline Mollinedia engleriana Perkins & Monimiaceae & 27 & 1,41 & 22 & 0,72 & 4,46 \\
\hline Mollinedia uleana Perkins & Monimiaceae & 30 & 1,57 & 25 & 0,48 & 4,31 \\
\hline Mollinedia gilgiana Perkins & Monimiaceae & 28 & 1,47 & 27 & 0,41 & 4,2 \\
\hline Ardisia martiana Miq. & Primulaceae & 35 & 1,83 & 28 & 0,2 & 4,19 \\
\hline Calyptranthes strigipes O. Berg & Myrtaceae & 30 & 1,57 & 25 & 0,36 & 4,05 \\
\hline Ocotea dispersa (Ness \& Mart.) Mez & Lauraceae & 18 & 0,94 & 17 & 0,68 & 3,56 \\
\hline Myrciaria floribunda $(\mathrm{H}$. West ex Willd.) O. Berg & Myrtaceae & 17 & 0,89 & 16 & 0,72 & 3,52 \\
\hline Cryptocarya saligna Mez & Lauraceae & 18 & 0,94 & 17 & 0,57 & 3,33 \\
\hline Marlierea tomentosa Cambess. & Myrtaceae & 20 & 1,05 & 19 & 0,41 & 3,23 \\
\hline Myrceugenia myrcioides (Cambess.) O. Berg & Myrtaceae & 22 & 1,15 & 19 & 0,32 & 3,15 \\
\hline Psychotria vellosiana Benth. & Rubiaceae & 26 & 1,36 & 23 & 0,09 & 3,14 \\
\hline Neomitranthes glomerata D. Legrand & Myrtaceae & 14 & 0,73 & 14 & 0,65 & 3,08 \\
\hline Guatteria australis A. St. Hil & Annonaceae & 22 & 1,15 & 18 & 0,28 & 3 \\
\hline Pouteria gardneriana (A. DC.) Radlk. & Sapotaceae & 12 & 0,63 & 11 & 0,7 & 2,88 \\
\hline Bathysa mendoncaei K. Schum. & Rubiaceae & 23 & 1,2 & 20 & 0,12 & 2,83 \\
\hline Ocotea catharinensis Mez & Lauraceae & 9 & 0,47 & 8 & 0,77 & 2,68 \\
\hline Cupania oblongifolia Mart. & Sapindaceae & 18 & 0,94 & 16 & 0,25 & 2,58 \\
\hline Syagrus pseudococos (Raddi) Glassman & Arecaceae & 17 & 0,84 & 16 & 0,22 & 2,4 \\
\hline Myrcia richardiana (O. Berg) Kiaersk. & Myrtaceae & 11 & 0,58 & 9 & 0,49 & 2,25 \\
\hline Machaerium dimorphandrum Hoehnc & Fabaceae & 9 & 0,47 & 7 & 0,6 & 2,25 \\
\hline Ecclinusa ramiflora Mart. & Sapotaceae & 10 & 0,52 & 10 & 0,47 & 2,22 \\
\hline Cyathea delgadii Sternb. & Cyatheaceae & 19 & 1 & 13 & 0,15 & 2,21 \\
\hline Schefflera calva (Cham.) Frodin \& Fiaschi & Araliaceae & 17 & 0,89 & 15 & 0,13 & 2,21 \\
\hline Eugenia copacabanensi Kiaersk. & Myrtaceae & 10 & 0,52 & 10 & 0,46 & 2,21 \\
\hline
\end{tabular}


Apêndice 2.

(Continua)

\begin{tabular}{|c|c|c|c|c|c|c|}
\hline Espécies & Família & NInd & RelDe & NAm & AbsDo & IVI \\
\hline Amaioua intermedia Mart. & Rubiaceae & 13 & 0,68 & 11 & 0,35 & 2,19 \\
\hline Eugenia sp.2 & Myrtaceae & 18 & 0,94 & 15 & 0,1 & 2,19 \\
\hline Chrysophyllum flexuosum Mart. & Sapotaceae & 9 & 0,47 & 9 & 0,5 & 2,15 \\
\hline Hirtella hebeclada Moric. Ex DC. & Chrysobalanaceae & 12 & 0,63 & 12 & 0,3 & 2,09 \\
\hline Matayba juglandifolia Radlk. & Sapindaceae & 13 & 0,68 & 12 & 0,25 & 2,04 \\
\hline Cedrela fissilis Vell. & Meliaceae & 11 & 0,58 & 10 & 0,36 & 2,03 \\
\hline Calyptranthes lucida Mart. ex DC & Myrtaceae & 14 & 0,73 & 11 & 0,24 & 2 \\
\hline Ocotea elegans Mez & Lauraceae & 15 & 0,79 & 11 & 0,17 & 1,91 \\
\hline Eugenia sp.3 & Myrtaceae & 16 & 0,84 & 12 & 0,09 & 1,86 \\
\hline Miconia cabucu Hoehne & Melastomataceae & 7 & 0,37 & 7 & 0,47 & 1,84 \\
\hline Sloanea monosperma Vell. & Elaeocarpaceae & 9 & 0,47 & 9 & 0,34 & 1,82 \\
\hline Matayba intermedia Mart. & Sapindaceae & 6 & 0,31 & 6 & 0,5 & 1,79 \\
\hline Guarea macrophylla Vahl & Meliaceae & 13 & 0,68 & 12 & 0,11 & 1,73 \\
\hline Psychotria nuda (Cham. \& Schltdl.) Wawra & Rubiaceae & 13 & 0,68 & 12 & 0,05 & 1,61 \\
\hline Ocotea glaziovii Mez & Lauraceae & 8 & 0,42 & 7 & 0,32 & 1,59 \\
\hline Aiouea acarodomatifera Kosterm. & Lauraceae & 3 & 0,16 & 2 & 0,57 & 1,51 \\
\hline Mouriri chamissoana Cogn. & Melastomataceae & 11 & 0,58 & 11 & 0,07 & 1,48 \\
\hline Gomidesia spectabilis (DC.) O. Berg & Myrtaceae & 12 & 0,63 & 10 & 0,08 & 1,48 \\
\hline Calyptranthes grandifolia O. Berg & Myrtaceae & 11 & 0,58 & 10 & 0,1 & 1,47 \\
\hline Faramea pachyantha Mull. Arg. & Rubiaceae & 11 & 0,58 & 10 & 0,08 & 1,43 \\
\hline Couepia venosa Prance & Chrysobalanaceae & 8 & 0,42 & 8 & 0,19 & 1,38 \\
\hline Chrysophyllum dusenii Cronquist & Sapotaceae & 6 & 0,31 & 6 & 0,3 & 1,37 \\
\hline Ouratea parviflora (A. DC.) Baill. & Lauraceae & 11 & 0,58 & 8 & 0,04 & 1,21 \\
\hline Myrtaceae sp.3 & Myrtaceae & 9 & 0,47 & 7 & 0,1 & 1,16 \\
\hline Hyeronima alchorneoides Allemão & Euphorbiaceae & 7 & 0,37 & 5 & 0,2 & 1,14 \\
\hline Miconia brasiliensis (Spreng.) Triana & Melastomataceae & 9 & 0,47 & 7 & 0,05 & 1,06 \\
\hline Cryptocarya mandioccana Meisn. & Lauraceae & 5 & 0,26 & 5 & 0,19 & 1,01 \\
\hline Eugenia cuprea (O. Berg) Mattos & Myrtaceae & 5 & 0,26 & 5 & 0,18 & 1 \\
\hline Casearia obliqua Spreng. & Salicaceae & 3 & 0,16 & 3 & 0,29 & 0,99 \\
\hline Beilschmiedia emarginata (Meisn.) Kosterm. & Lauraceae & 5 & 0,26 & 5 & 0,18 & 0,98 \\
\hline Solanum pseudoquina A. St. Hil & Solanaceae & 6 & 0,31 & 6 & 0,12 & 0,98 \\
\hline Pouteria psammophila (Mart.) Radlk. & Sapotaceae & 6 & 0,31 & 6 & 0,11 & 0,97 \\
\hline Copaifera trapezifolia Hayne & Fabaceae & 3 & 0,16 & 3 & 0,27 & 0,94 \\
\hline Ocotea daphnifolia (Meisn.) Mez & Lauraceae & 7 & 0,37 & 7 & 0,03 & 0,91 \\
\hline Cupania vernalis Cambess. & Sapindaceae & 6 & 0,31 & 6 & 0,08 & 0,9 \\
\hline Cyathea dichromatolepis Mart. & Cyatheaceae & 7 & 0,37 & 7 & 0,02 & 0,89 \\
\hline Faramea picinguabae M. Gomes & Rubiaceae & 5 & 0,26 & 5 & 0,13 & 0,89 \\
\hline Inga capitata Desv. & Fabaceae & 6 & 0,31 & 6 & 0,06 & 0,85 \\
\hline Cordia sellowiana Cham. & Boraginaceae & 4 & 0,21 & 3 & 0,2 & 0,85 \\
\hline Tachigali multijuga Benth. & Fabaceae & 5 & 0,26 & 4 & 0,12 & 0,8 \\
\hline Ocotea bicolor Vattimo-Gil & Lauraceae & 5 & 0,26 & 4 & 0,12 & 0,79 \\
\hline Heisteria silvianii Schwacke & Olacaceae & 5 & 0,26 & 5 & 0,07 & 0,75 \\
\hline Citronella paniculata (Mart.) R.A. Howard & Cardiopteridaceae & 4 & 0,21 & 4 & 0,12 & 0,74 \\
\hline
\end{tabular}


Apêndice 2.

(Continua)

\begin{tabular}{|c|c|c|c|c|c|c|}
\hline Espécies & Família & NInd & RelDe & NAm & AbsDo & IVI \\
\hline Copaifera langsdorffii Desf. & Fabaceae & 5 & 0,26 & 5 & 0,05 & 0,71 \\
\hline Citronella megaphylla (Miers) Howard & Cardiopteridaceae & 5 & 0,26 & 5 & 0,05 & 0,7 \\
\hline Coussapoa microcarpa Schott) Rizzini & Moraceae & 2 & 0,1 & 2 & 0,21 & 0,69 \\
\hline Eugenia cerasiflora Miq. & Myrtaceae & 5 & 0,26 & 5 & 0,03 & 0,68 \\
\hline Miconia tristis Spring & Melastomataceae & 5 & 0,26 & 5 & 0,03 & 0,68 \\
\hline Inga striata Benth. & Fabaceae & 3 & 0,16 & 3 & 0,14 & 0,66 \\
\hline Myrtaceae sp.4 & Myrtaceae & 4 & 0,21 & 4 & 0,08 & 0,65 \\
\hline Guatteria hilariana Engl. & Annonaceae & 5 & 0,26 & 5 & 0,02 & 0,64 \\
\hline Inga hispida Schott. ex. Benth. & Fabaceae & 5 & 0,26 & 5 & 0,02 & 0,64 \\
\hline Ocotea aciphylla (Ness \& Mart.) Mez & Lauraceae & 2 & 0,1 & 1 & 0,21 & 0,63 \\
\hline Matayba guianensis Aubl. & Sapindaceae & 4 & 0,21 & 4 & 0,07 & 0,63 \\
\hline Andira fraxinifolium Benth. & Fabaceae & 2 & 0,1 & 2 & 0,18 & 0,63 \\
\hline Cyathea phalerata Mart. & Cyatheaceae & 4 & 0,21 & 4 & 0,04 & 0,57 \\
\hline Sapium glandulatum (Vell.) Pax & Euphorbiaceae & 4 & 0,21 & 4 & 0,04 & 0,57 \\
\hline Pouteria venosa (Mart.) Baehni & Sapotaceae & 3 & 0,16 & 3 & 0,09 & 0,56 \\
\hline Byrsonima ligustrifolia Adr. Juss & Malpighiaceae & 2 & 0,1 & 2 & 0,14 & 0,55 \\
\hline Zollernia ilicifolia (Brongn.) Vogel & Fabaceae & 4 & 0,21 & 4 & 0,02 & 0,52 \\
\hline Randia armata (Sw.) DC. & Rubiaceae & 2 & 0,1 & 2 & 0,12 & 0,51 \\
\hline Dendropanax monogynus (Vell.) Seem. & Araliaceae & 4 & 0,21 & 4 & 0,01 & 0,51 \\
\hline Maytenus schumanniana Loes. & Celastraceae & 1 & 0,05 & 1 & 0,18 & 0,5 \\
\hline Myrtaceae sp.1 & Myrtaceae & 3 & 0,16 & 3 & 0,06 & 0,49 \\
\hline Symplocos estrellensis Casar. & Symplocaceae & 3 & 0,16 & 3 & 0,02 & 0,41 \\
\hline Chrysophyllum sp. & Sapotaceae & 2 & 0,1 & 2 & 0,08 & 0,41 \\
\hline Pouteria caimito (Ruiz \& Pav.) Radlk. & Sapotaceae & 1 & 0,05 & 1 & 0,13 & 0,41 \\
\hline Hymenolobium janeirense Kuhlm. & Fabaceae & 3 & 0,16 & 3 & 0,02 & 0,4 \\
\hline Ocotea aff. Teleiandra (Meisn.) Mez & Lauraceae & 3 & 0,16 & 3 & 0,01 & 0,38 \\
\hline Campomanesia phaea (O. Berg) Landrum & Myrtaceae & 1 & 0,05 & 1 & 0,11 & 0,37 \\
\hline Cecropia ulei Snethl & Urticaceae & 2 & 0,1 & 2 & 0,04 & 0,33 \\
\hline Ficus luschnathiana Miq. & Moraceae & 2 & 0,1 & 2 & 0,04 & 0,32 \\
\hline Tibouchinia pulchra Cogn. & Melastomataceae & 1 & 0,05 & 1 & 0,09 & 0,31 \\
\hline Piper cernum Vell. & Piperaceae & 4 & 0,21 & 1 & 0,01 & 0,3 \\
\hline Ocotea venulosa (Nees) Baitello & Lauraceae & 2 & 0,1 & 2 & 0,03 & 0,3 \\
\hline Allophylus petiolatus Radlk. & Sapindaceae & 2 & 0,1 & 2 & 0,02 & 0,29 \\
\hline Ocotea odorifera (Vell.) Rohwer & Lauraceae & 2 & 0,1 & 2 & 0,02 & 0,28 \\
\hline Cocoloba striata Benth. & Poligonacaceae & 2 & 0,1 & 2 & 0,02 & 0,28 \\
\hline Myrtaceae sp.2 & Myrtaceae & 2 & 0,1 & 2 & 0,02 & 0,28 \\
\hline Rudgea vellerea Mull. Arg. & Rubiaceae & 2 & 0,1 & 2 & 0,02 & 0,28 \\
\hline Ocotea silvestres Vattimo-Gil & Lauraceae & 2 & 0,1 & 2 & 0,01 & 0,27 \\
\hline Lamanonia ternata Vell. & Cunoniaceae & 1 & 0,05 & 1 & 0,07 & 0,27 \\
\hline Inga sellowiana Benth. & Fabaceae & 2 & 0,1 & 2 & 0,01 & 0,26 \\
\hline Campomanesia guaviroba (C.C.) Keaersk & Myrtaceae & 2 & 0,1 & 2 & 0,01 & 0,26 \\
\hline Aniba firmula (Nees \& Mart.) Mez & Lauraceae & 2 & 0,1 & 2 & 0,01 & 0,26 \\
\hline Calyptranthes guianensis Willd. & Myrtaceae & 2 & 0,1 & 2 & 0,01 & 0,26 \\
\hline
\end{tabular}


Apêndice 2.

(Conclusão)

\begin{tabular}{|c|c|c|c|c|c|c|}
\hline Espécies & Família & NInd & RelDe & NAm & AbsDo & IVI \\
\hline Matayba elaeaginoides Radlk. & Sapindaceae & 2 & 0,1 & 2 & 0,01 & 0,26 \\
\hline Jacaranda puberula Cham. & Bignoniaceae & 1 & 0,05 & 1 & 0,06 & 0,25 \\
\hline Tibouchinia arborea Cogn. & Melastomataceae & 1 & 0,05 & 1 & 0,05 & 0,23 \\
\hline Alsophila sternbergii (Sternb.) D.S. Conant & Cyatheaceae & 2 & 0,1 & 1 & 0,02 & 0,22 \\
\hline Ocotea brachybotrya (Meisn.) Mez & Lauraceae & 1 & 0,05 & 1 & 0,04 & 0,21 \\
\hline Eugenia sp.1 & Myrtaceae & 2 & 0,1 & 1 & 0,02 & 0,21 \\
\hline Tontelea leptophylla A. C. Sm. & Celastraceae & 1 & 0,05 & 1 & 0,02 & 0,17 \\
\hline Trigynaea oblongifolia Schltdl. & Annonaceae & 1 & 0,05 & 1 & 0,02 & 0,16 \\
\hline Brosimum acutifolium Huber & Moraceae & 1 & 0,05 & 1 & 0,01 & 0,15 \\
\hline Heisteria ovata Benth. & Olacaceae & 1 & 0,05 & 1 & 0,01 & 0,14 \\
\hline Ilex theezans Mart. & Aquifoliaceae & 1 & 0,05 & 1 & 0,01 & 0,14 \\
\hline Astrocaryum aculeatissimum (Schott) Burret & Arecaceae & 1 & 0,05 & 1 & 0,01 & 0,14 \\
\hline Ocotea spectabilis (Meisn.) Mez & Lauraceae & 1 & 0,05 & 1 & 0,01 & 0,13 \\
\hline Duguetia lanceolata A. St. - Hil. & Annonaceae & 1 & 0,05 & 1 & 0 & 0,13 \\
\hline Miconia budlejoides Triana & Melastomataceae & 1 & 0,05 & 1 & 0 & 0,13 \\
\hline Zygia latifolia var. glabrata Barneby \& J.W. Grimes & Fabaceae & 1 & 0,05 & 1 & 0 & 0,13 \\
\hline Picramnia ciliata Mart. & Picramniaceae & 1 & 0,05 & 1 & 0 & 0,13 \\
\hline Ocotea aff. lancifolia Mart. & Lauraceae & 1 & 0,05 & 1 & 0 & 0,13 \\
\hline Malouetia arborea (Vell.) Miers & Apocynaceae & 1 & 0,05 & 1 & 0 & 0,13 \\
\hline Ilex amara (Vell.) Loes. & Aquifoliaceae & 1 & 0,05 & 1 & 0 & 0,13 \\
\hline Alsophila setosa Kaulf. & Cyatheaceae & 1 & 0,05 & 1 & 0 & 0,13 \\
\hline Rhodostemonodaphne macrocalyx Rohwer ex Madriñán & Lauraceae & 1 & 0,05 & 1 & 0 & 0,13 \\
\hline Myrcia splendens Sw. CD. & Myrtaceae & 1 & 0,05 & 1 & 0 & 0,13 \\
\hline Total & & 1.768 & 92,42 & 1.383 & 42,76 & 279,16 \\
\hline
\end{tabular}

